\title{
Assessing Prone Areas to Heavy Rainfall and the Impaction of the Upper Warm Temperature Anomaly during March-May Rainfall Season in Tanzania
}

\author{
Kantamla Biseke Mafuru $\mathbb{D i D}^{1,2,3}$ and Tan Guirong $\mathbb{D}^{1}$ \\ ${ }^{1}$ Key Laboratory of Meteorological Disaster, Ministry of Education (KLME), Joint International Research Laboratory of \\ Climate and Environment Change (ILCBC), Collaborative Disasters (CIC-FEMD), Nanjing 210044, China \\ ${ }^{2}$ College of Atmospheric Sciences, Nanjing University of Information Science and Technology, Nanjing, Jiangsu 210044, China \\ ${ }^{3}$ Tanzania Meteorological Agency, Dar es Salaam, Tanzania
}

Correspondence should be addressed to Tan Guirong; tanguirong@nuist.edu.cn

Received 17 August 2017; Revised 12 January 2018; Accepted 11 June 2018; Published 24 July 2018

Academic Editor: Hisayuki Kubota

Copyright (c) 2018 Kantamla Biseke Mafuru and Tan Guirong. This is an open access article distributed under the Creative Commons Attribution License, which permits unrestricted use, distribution, and reproduction in any medium, provided the original work is properly cited.

\begin{abstract}
This study analyses the spatial and temporal distribution of heavy rainfall events (HREs) and its associated circulation anomalies over Tanzania during March to May (MAM) rainfall season of 1980-2010. A total of 822 HREs were revealed, concentrated over the northern sector (NS) of the country. Years with anomalous HREs are associated with low-level westerly convergence, advection of moisture from both the Indian Ocean and Congo basin, an upper warm temperature anomaly (UWTA), intensified and well-positioned Intertropical Convergence Zone (ITCZ), and pronounced rising motion since the ascending limb of the Walker type of circulation is centered over Tanzania. The analysis of the UWTA in this study has brought a key factor in exploring the possible likely cause and improved early warning system for the HREs during the MAM rainfall season in Tanzania. Making use of the thermal wind equation and the velocity divergent form of the continuity equation (DFCE), we found that the UWTA results into an upper-level horizontal wind divergence which significantly accelerates vertical ascent, deepening the surface low pressure for an enhanced convective process and HREs formation.
\end{abstract}

\section{Introduction}

In recent years, Tanzania has repeatedly experienced disastrous impacts of heavy rains. These heavy rains have led to a wide spread flood resulting in extensive economic damages and casualties. Studies from EMDAT [1], an internationally reported loss, pointed out that, between 1990 and 2010, flooding events have become the most devastating catastrophe among the natural disasters which have been affecting the country. Three of the recent dramatic events include the catastrophic heavy rainfall event that occurred in December 2011 over northeastern highlands (NEH), southwestern highlands (SWH), and Dar es Salaam. It ended up with destructive flooding, triggering landslides, killing at least two dozen of people and leaving more than 10,000 displaced. A report from Tanzania Meteorological Agency
(TMA) confirmed that it was the most intense rain that Tanzania has experienced since her independence in 1961 that killed at least 20 people in the main city of Dar es Salaam while 5000 people remained homeless.

On 11 April 2014, Dar es Salaam recorded a rainfall of $135 \mathrm{~mm}$ in 24 hours which lead to flooding that left at least 41 people dead. The scenario was followed by another heavy fall over SWH killing at least 3 people. TMA confirmed heavy fall had occurred in Kahama District (Lake Victoria basin) on the 3 May 2015 leading to tremendous floods with 42 people losing their lives, 91 people seriously injured, and 160 houses destructed while 3500 people were affected. Later on the 6 and 7 May 2015, heavy fall was reported in most areas of the northern coast with $110 \mathrm{~mm}$ and $52.5 \mathrm{~mm}$ of rains recorded in Dar es Salaam Airport in respective dates. The scenario ended into heavy floods with 12 death tolls and 
severe destruction to infrastructures, while 3000 people were displaced over the NEH.

Rain-fed farming characterizes most of sub-Saharan Africa, where $95 \%$ of the total cultivated area depends on rainfall, and determines the livelihoods of $70 \%$ of the population [2, 3]. Being one among the sub-Saharan Africa, agriculture in Tanzania strongly depends on rainfall and remains the largest sector in the economy. Its performance has a significant effect on output, corresponding income, and poverty level eradication. Sales of agricultural products account for about 70 percent of rural household incomes and the sector in general accounts for about half of gross domestic product and exports, where its importance is amplified through backward and forward linkage effects. Assessing the spatial distribution, changing trends and a formation mechanism of heavy rainfall [4-7] in Tanzania is of crucial importance towards earning maximum agricultural products and saving people's lives.

The knowledge of extreme precipitation frequency in the present climate and the projections for the future can provide useful information to agriculture and hydrology sectors. It also reduces food insecurity and accelerates poverty reduction particularly in rural areas which require an increase in agricultural productivity, higher added value, and improved producer price incentives. The knowledge of the interaction of these extreme events with large-scale atmospheric and oceanic circulation as well as with synoptic and mesoscale conditions is a key as it improves the early warning system (EWS). Therefore, there is a need to know not only the frequency of their episodes but also the intensity and the associated mechanisms to provide reliable information for early warning response.

A number of studies [8-11] revealed conditions for heavy rainfall formation require a massive supply of water vapor. Ding [8] concluded that, apart from the basic conditions (moisture, energy, and convection), strong convective systems need reinforcement (topographic effects and upper divergence) and strong vertical wind shear. Several studies have been carried out trying to relate the interannual variability of seasonal rainfall and associated circulation anomalies over East Africa. For instance, Camberlin and Philippon [12] found that the equatorial surface westerly flow anomalies from Congo are positively associated with the East African long rain (i.e., in hereafter MAM rainfall season) and it is this circulation anomaly that controls the location of the meridianally oriented Intertropical Convergence Zone (ITCZ).

Kijazi and Reason [13] found that increased fetch of lowlevel moisture flux anomalies from the Congo basin and the tropical Indian Ocean can result in the increase in MAM rainfall over Tanzania. Meanwhile, Nicholson [14-16] noted that the intensity and location of rainfall over the eastern Africa are strongly associated with the meridianally aligned ITCZ into which the humid south Atlantic air-masses converge with the Indian Ocean trade winds. The westerly flow of the moist South Atlantic air masses on the contrary is found to be strongly associated with East African rainfall reception [14-19]. In his investigation, McHugh [16] realized the fact that, westerly flow anomalies across East
Africa are associated with anomalous precipitable water, moist static instability, convergence uplift, and rainfall anomalies. During boreal spring, the convectively coupled Kelvin waves (CCKWs) have strong seasonality and interannual variability that propagate eastwards from equatorial South America to tropical Atlantic and Africa, thereby acting as the bridge linking convection and precipitation in these three regions [20].

The CCKWs enhance convection, strengthen cloud development, and increase rainfall through low-level zonal moisture flux [21, 22]. However, the variation in cloudiness associated with the CCKWs peak along the latitude of the climatological ITCZ in Africa, and it considerably varies with season [22]. Wheeler et al. [23] noted that the eastward moving wave (i.e., enhanced convection) is flanked by moisture flux divergence (convergence) to the west (east). It is the moisture flux convergence that leads into enhanced convection.

Also, some researchers $[18,24-27]$ relate the El-Niño Southern Oscillation (ENSO) modulation with rainfall variability over East Africa but the modulation during the MAM rainfall season over Tanzania (i.e., northern coastal belt) is found to be of lesser extent [28]. Works of Mutai and Ward [18, 29-32], based on different temporal and spatial scales, did not show any significant correlation between the East Africa long rain season and either the atmospheric or oceanic component of ENSO. Rowell et al. [32] noted that a poor or late start of the MAM season was associated with a cool tropical North Atlantic. Toward the end of the long rains (i.e., in May), positive correlations are found in the extratropical Southwest Atlantic and more extensively in the equatorial Indian Ocean. Okoola [33] and Hills [34] found an association between wind circulation patterns and rainfall over East Africa. Increased rainfall over East Africa was also associated with the occurrence of an anomalous cyclonic circulation over the western Indian Ocean [35]. Furthermore, a shift in the location of the ascending and descending branch of the Walker circulation is linked to rainfall variability over East Africa that occurs in association with tropical SST and convection anomalies [36]. Regions of vertical motion associated with an interaction between mesoscale and large-scale flows have also been linked to precipitation distribution over East Africa [37-39].

But in some areas within the region, the reduction in MAM rainfall reception associates with statistically significant negative precipitable water anomalies across East Africa and strengthened northeasterly trade winds from Sudan across the Equatorial Africa to the Atlantic Ocean which hinders the influx of unstable moist air masses from the west [40]. Williams and Funk [41] related it to the westward extension of the Indo-Pacific warm pool and associated Walker circulation, while Lyon and DeWitt [42] and Lyon et al. [43] linked it to a shift of sea surface temperature (SST) over the Pacific basin to a La Niña-like pattern.

Although all the research findings are performed on the associated circulation anomalies, the research results failed to identify any strong and robust atmospheric or oceanic forcing of the East African March-May rains. This partly arises from the fact that the long rains in boreal spring 
exhibits much more inconsistent variations from station to station which is becoming harder in relating to anomalies of the climate system making it difficult even in its predictability $[12,14,44]$.

There is no doubt that a lot of research works have been done to explore climate change and variability over the East Africa region, but few studies have looked at the impacts of such variability in Tanzania especially on the repetitive heavy falls and its associated circulation weather anomalies. The majority of the researchers in East Africa have put more emphasis on the impact of surface/low-level circulation anomalies on climate variability, while less or no findings on the upper-level circulation anomalies within the region Tanzania in particular. This study aims at filling this gap by assessing (1) prone areas to heavy rainfall and (2) the influence of the upper temperature anomalies on heavy rainfall events (HREs) among other circulation anomalies to be included in this study during the March to May (MAM) season of 1980-2010 climatology in Tanzania. The analysis will add value to heavy rainfall forecasting, disaster warning, water resource utilization, and economy development (i.e., agricultural productivity). The first chapter introduces the study, while data description and methods used are in Section 2. Results and discussion are presented in Section 3, where the circulation anomalies of selected fields and the influence of the upper warm (cold) temperature anomalies to the mean MAM heavy rainfall are demonstrated. The summary and conclusion are given in Section 4, which summarizes our main findings and discusses them in the context of relevant literature.

\section{Data and Methodology}

Daily rain gauge records from sixteen (16) synoptic stations scattered throughout the country during the MAM season of 1981-2010 climatology were used in this study. The study adopted the eleven (11) homogeneous climatological zones used in MAM seasonal weather forecasting across the country. A heavy rainfall event (HRE) was defined as any amount $\geq 50 \mathrm{~mm} / 24$ hours from a given station. The threshold above was deemed relevant for many areas within the East African region following the workshop for Severe Weather Forecasting Demonstration Project-East Africa (SWFDP-EA) held in Arusha in December 2011. A number of researchers [45] have used the stated threshold value within the region. The trend of heavy rainfall of a particular station, an interannual variability of HREs, a spatial distribution of both the total events rainfall, and the ratio of events rainfall to MAM season were determined from the above selection. Empirical orthogonal function (EOF) was performed on the mean MAM seasonal HREs to identify areas prone to HREs. To further understand the atmospheric circulation patterns behind the influence of heavy rainfall during the period of study, reanalysis fields from National Centers for Environmental Prediction/National Center for Atmospheric Research (NCEP/NCAR) were used similarly to Kalnay et al. [46]. The spatial resolution of the data was $2.5^{\circ} \times 2.5^{\circ}$, and the analysis was performed over domain extending from $20^{\circ} \mathrm{W}$ to $180^{\circ} \mathrm{E}$ and $60^{\circ} \mathrm{S}$ to $60^{\circ} \mathrm{N}$.
A nonparametric test, Mann-Kendall trend test (MK trend test) $[47,48]$, was used to detect the trend in time series of HREs and their corresponding significance in respective stations. The linkage between circulation anomalies with the periods of anomalous/suppressed HREs was done with the aid of the composite analysis method. Based on principal component (PC) time series of the first EOF (PC-1), years with strong amplitudes of normalized heavy rainfall departures greater than +1 (less than -1 ) of the standard deviation were classified as years with anomalous (suppressed) HREs during the entire climatology of the study.

\section{Results and Discussion}

The results obtained in this study are discussed in four subsections. We first give detailed information on the spatial and temporal distribution of HREs. Later on, we discuss circulation anomalies linked to HREs.

3.1. Spatial and Temporal Distribution of HREs. A precise analysis of heavy rainfall revealed 822 HREs. The number of events is found to be concentrated over the eastern and northern parts of the country with the highest concentration along the coastal belt (e.g., Northern coast) and western part of the Lake Victoria basin (Figure 1(b)). Meanwhile, the total amount of heavy rainfall tends to be heavier in areas with highest number of HREs (figure not included). The MAM rainfall climatology (Figure 1(a)) shows a unimodal rainfall pattern with western, central, and southwestern highlands, and southern regions were characterized by low rainfall. The eastern and northern sector (NS) experienced a bimodal rainfall pattern that shows enhanced amount of heavy rainfall mainly along the costal belt (particularly the northern coast) and western part of the Lake Victoria basin. Figure 1(a) shows the long-term mean (LTM) of March-May rainfall distribution closely resembling that of the number of HREs (Figure 1(b)). This suggests a significant contribution of the amount of heavy rainfall to the total MAM rainfall. Over the entire period of study, it was observed that HREs contributed $23.94 \%$ of the total amount of MAM rainfall. The coastal belt (Dar es Salaam, Tanga, Pemba, and Mtwara) contributed $13.48 \%$ while the Lake Victoria basin (Mwanza, Bukoba, and Musoma) contributed $4.35 \%$. Other contributions are as follows: NEH (KIA, Arusha, and Moshi, 3.62\%) and Western areas (Kigoma and Tabora, $1.14 \%$ ), while the remaining areas only $1.35 \%$.

An interannual variability of both the number of HREs (Figure 2(a)) and the total amount of rainfall due to HREs (Figure 2(b)) show a direct relationship, where the high number of HREs coincides with an enhanced total amount of rainfall during the MAM season. From 1995 to 2010, years with anomalous HREs (1995, 1997, 1998, 1999, and 2005) were more than those with suppressed HREs (2000 and 2003). During the period of study, April was more affected by heavy rainfall and had a significant contribution of the total amount of rainfall to the season than the rest of the months with 351 events followed by May (242 events) and March (229 events), as indicated in Figures 2(c) and 2(d). 

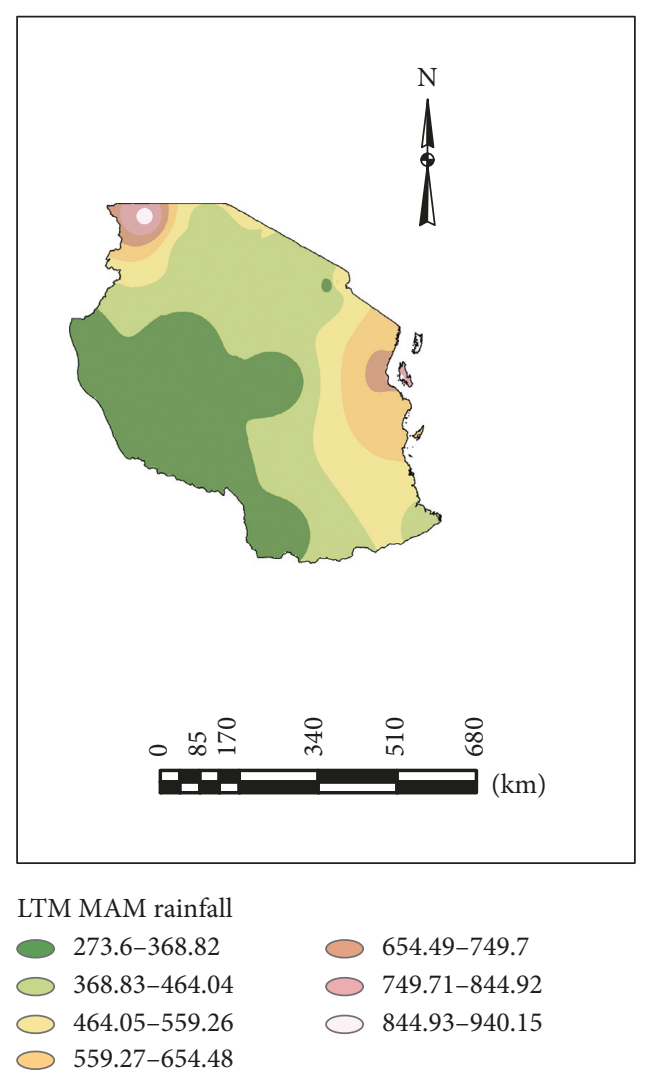

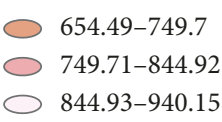

(a)

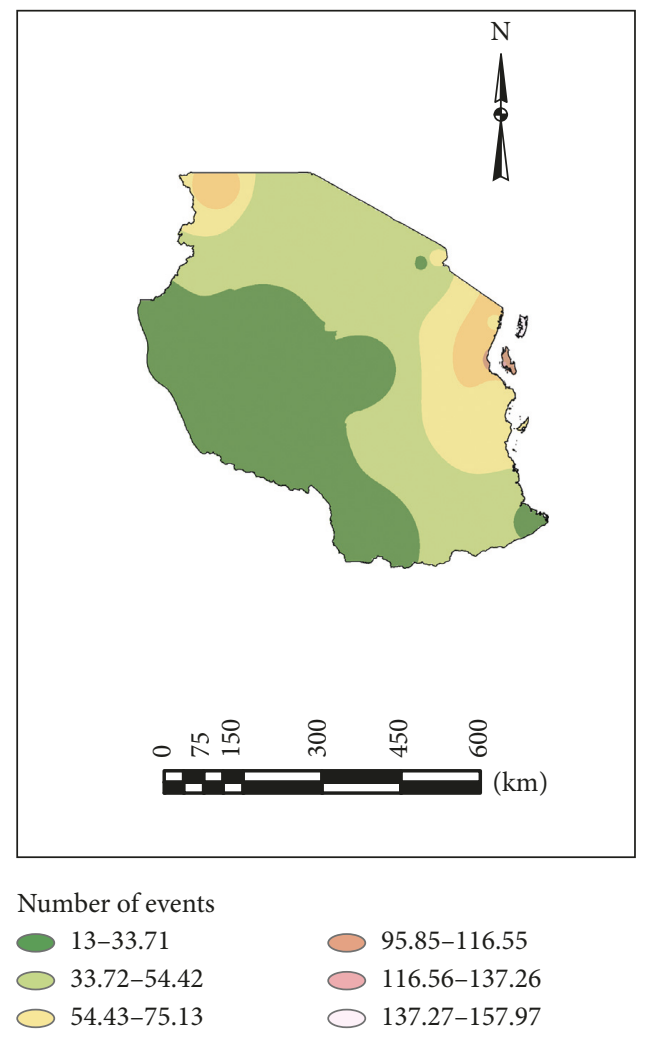

(b)

FIgURE 1: Spatial distribution pattern for (a) long-term mean of MAM rainfall (mm) and (b) number of HREs based on 1980-2010 climatology.

3.2. Temporal Distribution of MK Trend Test for HREs. The sequential MK trend test applied in this study graphically illustrates the forward, $u(F)$, and backward, $u(B)$, trends of heavy rainfall over the few selected stations out of 16 synoptic stations under studies (Figure 3). When a set of two series, a forward and backward one, cross each other and diverge beyond the specific threshold value (i.e., $\alpha=0.05$ significant level for this study), the point is said to be a significant change point. Mosmann et al. [49] assumed that the point is the approximate year when the trend begins, while Moraes et al. [50] referred to it as the period at which the critical point of change occurs. A typical sequential MK trend test over the Lake Victoria basin in Figures 3(a) and 3(b) shows that all stations were in favor of an increasing trend at 95\% confidence limit. Mwanza and Bukoba had insignificant change points at 95\% confidence interval. An abrupt change in the trend of heavy rainfall was observed over Bukoba in 2003, leaned towards increasing trend by which in 2008 a progressive series crosses the critical limit. In Moshi (Figure 3(c)), it is characterized by a positive trend which is insignificant at $95 \%$ confidence limit. It shows a period of abrupt declining in trend (1983-1988), the window into which stations over the Lake Victoria basin adopted. Changing points were not significant at 0.05 confidence level.

Generally, stations over the northern coast (Figures 3(d)-3(f)) are marked by an increasing trend of heavy rainfall and changing points/abrupt changes that were found between 2001 and 2010; it should be noted that both the trends and changing points were insignificant at 0.05 confidence level. However, the progressive and backward series for Arusha, Dar es Salaam, Dodoma, KIA, Kigoma, Mbeya, Musoma, and Tabora (i.e., figures not included in this study) were parallel to each other showing that there was no abrupt change in their trend during the entire period of study. Similarly, their progressive series, $u(F)$, was above the critical limit between 1993 and 2010, and therefore, there was a significant increase in trend at $95 \%$ confidence interval.

3.3. Prone Areas Suspicious to HREs. Figures 4(a), 5(a), and 5 (b)) display the spatial patterns of the first three EOF analysis of the mean HREs during the MAM season for 16 synoptic stations from 1980 to 2010 . The mentioned EOF patterns explain more than $45.17 \%$ of the total variance and are more representative of the country's seasonal rainfall. The spatial pattern of the first EOF mode (EOF-1) (Figure 4(a)) of the heavy rainfall anomalies accounts for $18.13 \%$ of the total variance during the season. Most of its eigenvector coefficients are positive with an exception over the central to southern sector of the study area. The highest values of positive coefficients are concentrated over NS of the country 


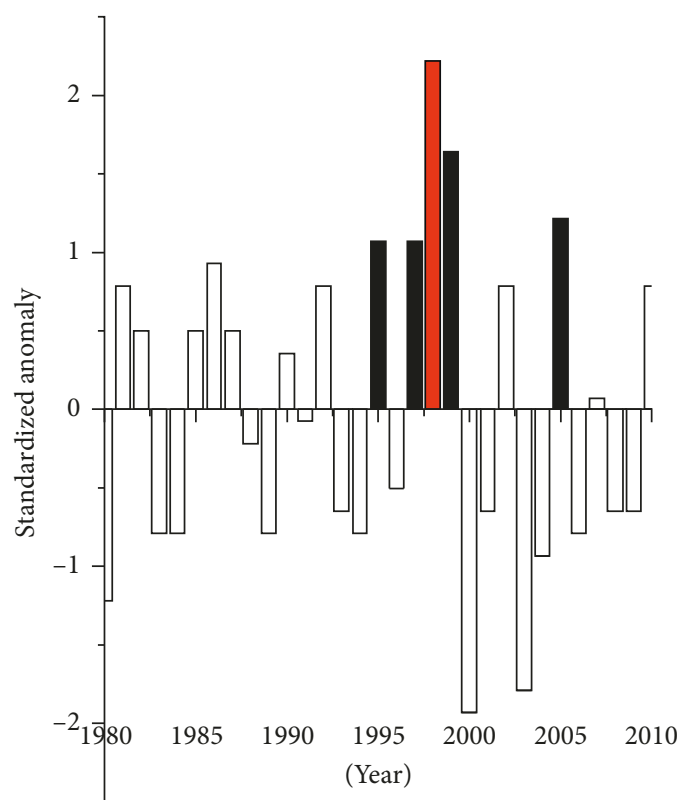

(a)

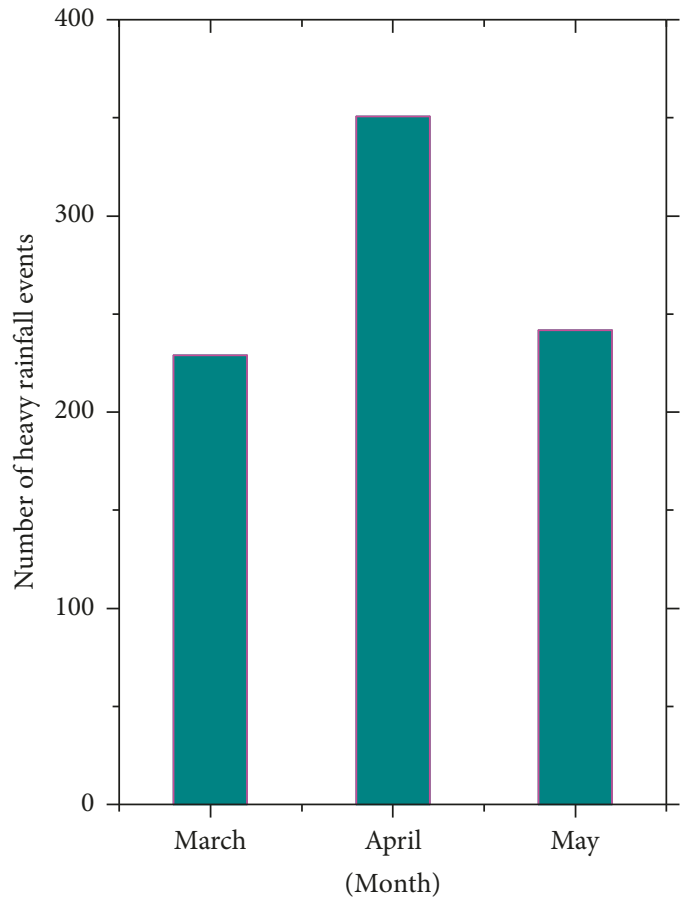

(c)

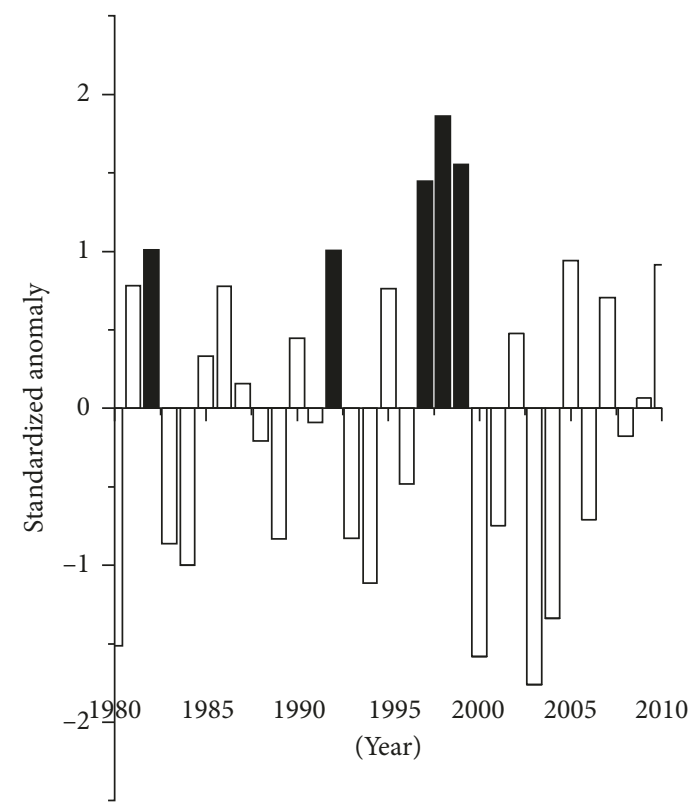

(b)

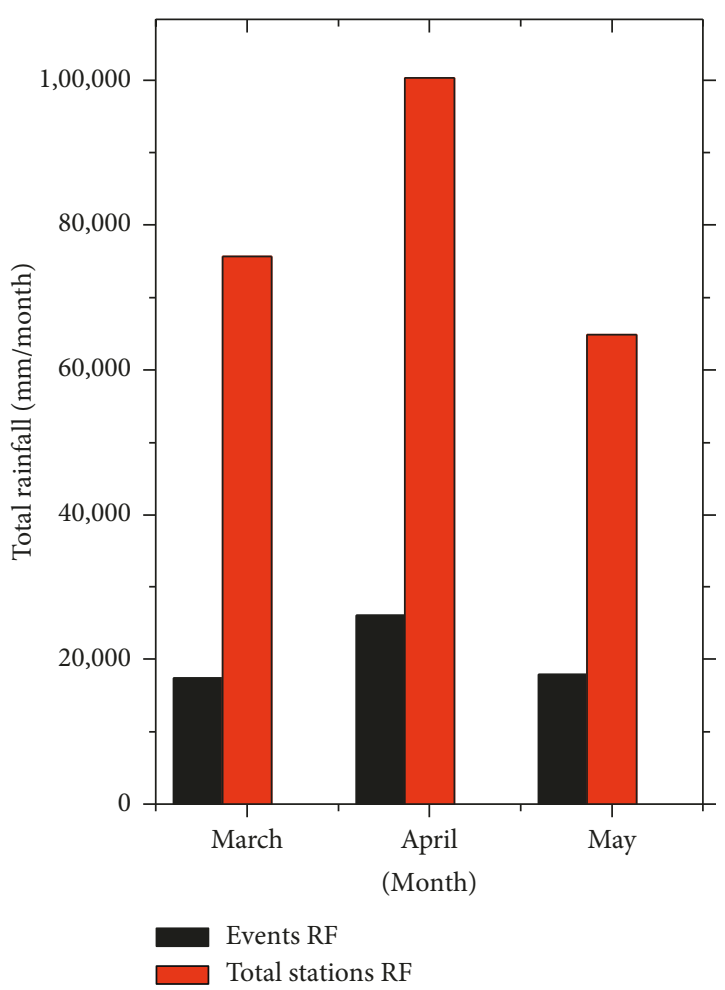

(d)

FIGURE 2: Interannual (top) and monthly (bottom) variability of (a, c) number of HREs and (b, d) total amount of rainfall due to HREs (mm) based on 1980-2010 climatology. Black bars in (a) and (b) represent events with standard deviation above 1, while the red bar in (a) denotes events with standard deviation above 2.

particularly the Lake Victoria Basin, NEH, Western, and over Extreme Northern coast.

The spatial pattern represented by EOF-2 and EOF-3 in Figure 5 accounts about $27.04 \%$ of the total variance of mean heavy rainfall during the MAM season. These patterns indicate the shift of high positive scores of eigenvectors towards the western side of the Lake Victoria basin and over the eastern sector particularly the Coastal Belt and its Hinterlands all the way to the southern region.

It should be noted that the principal component score time series provides an insight into the strength of an EOF pattern over time. In the results obtained from the first mode, 

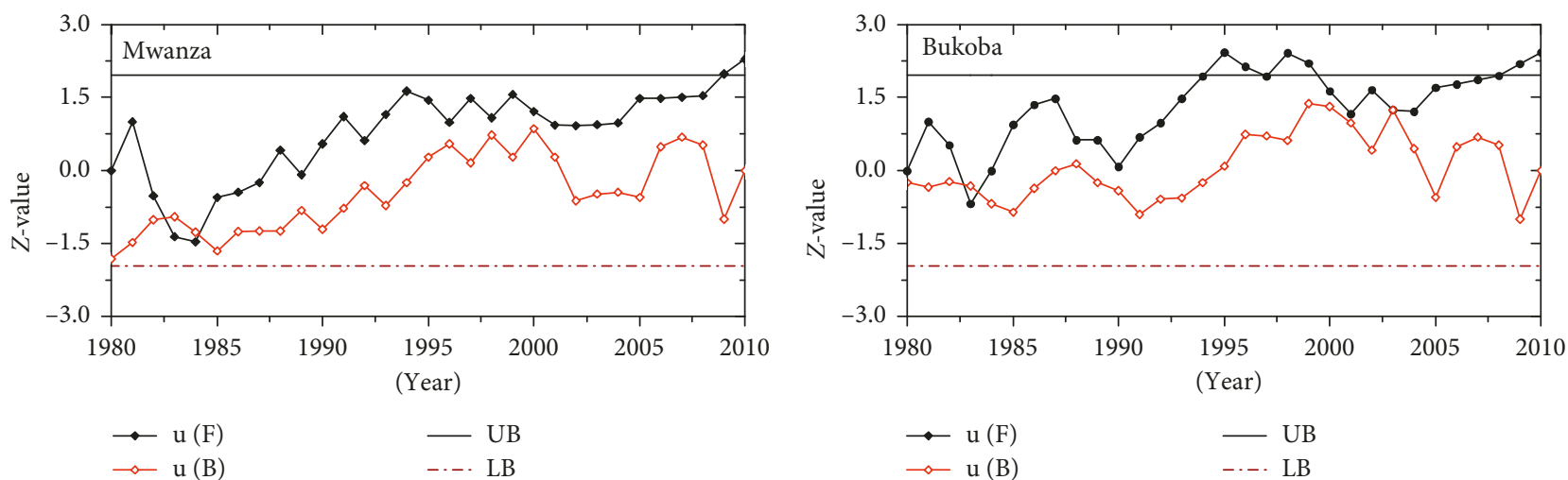

(a)

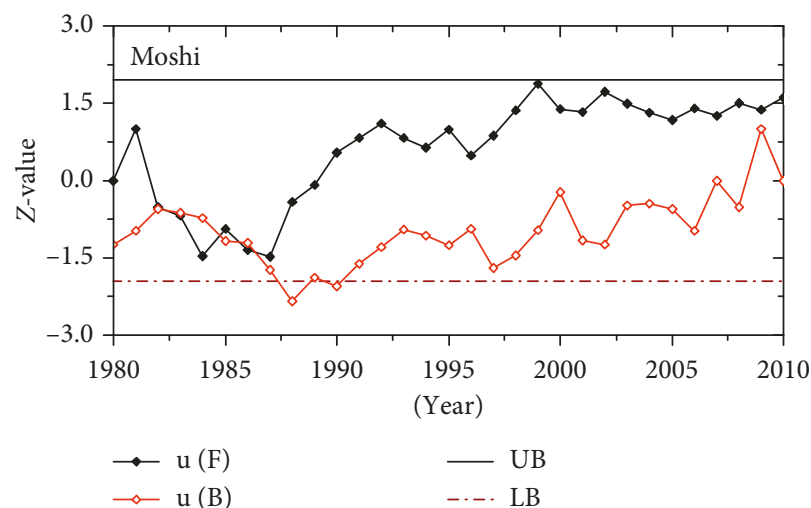

(b)

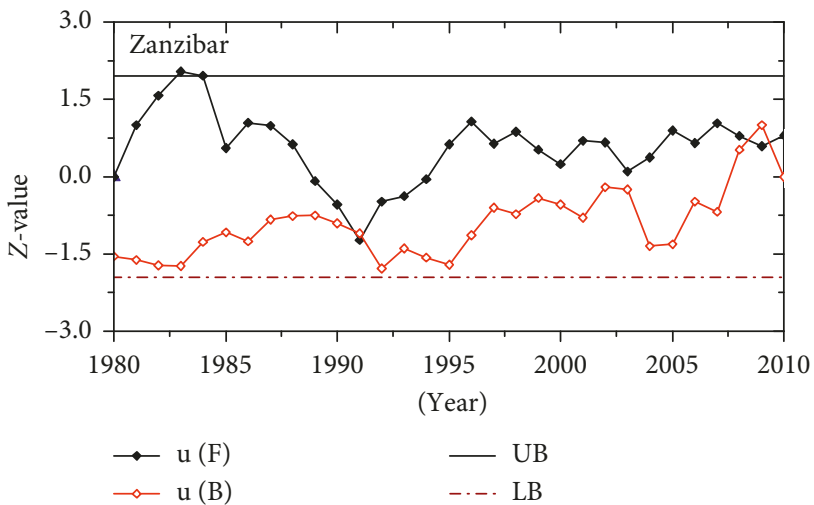

(c)

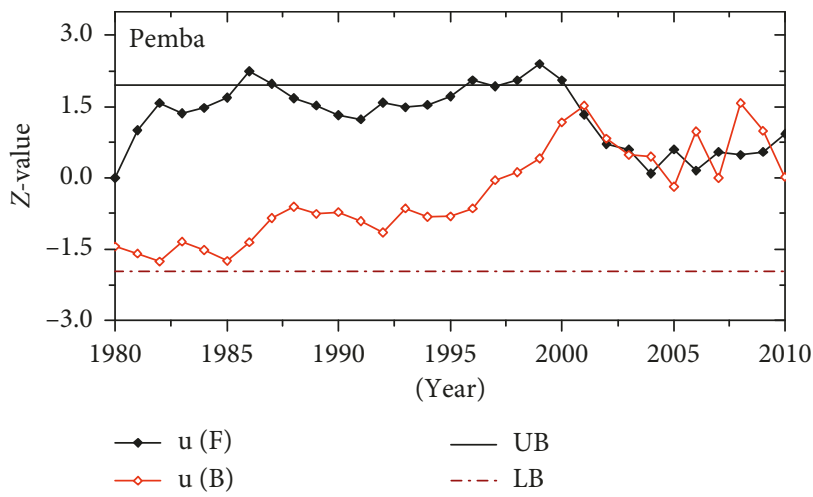

(e)

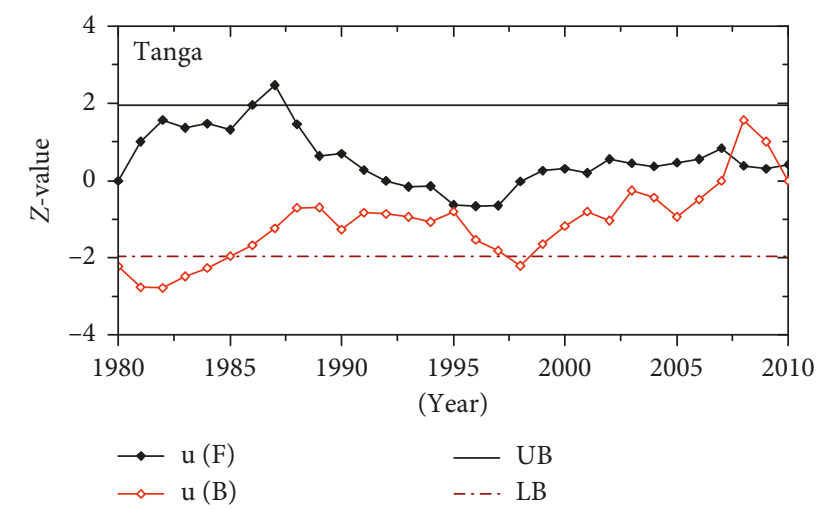

(f)

Figure 3: Sequential Mann-Kendall tests of annual heavy rainfall over (a, b) Lake Victoria basin, (c) NEH, and (d-f) northern coast. Dotted and solid horizontal lines indicate critical values corresponding to $95 \%$ confidence interval.

it shows that years with normalized heavy rainfall departures greater than one $(>+1)$ of the standard deviation were mainly observed in 1981, 1982, 1985, 1990, 1997, 1998, 1999, 2005, and 2010. On the contrary, years with normalized departures of less than minus one $(<-1)$ were observed in 1980, 1983, 1984, 1987, $1989,1991,1992$, and 2001. Some of these years (i.e., years with strong amplitude of greater than +1 or less than -1 of the standard deviation) were then used in the composite analysis method to find the possible circulation anomalies that were likely linked with pronounced HREs during the study period.

In general, the spatial patterns represented by EOF-1 to EOF-3 in Figures 4(a), 5(a), and 5(b) are in agreement with the results obtained in Figure 1(a) which signifies credible areas over the country that were mostly affected by heavy rainfall. These are the Coastal Belt and its hinterland, NEH, Lake Victoria basin, and some areas over the West (i.e., Tabora).

3.4. Circulation Anomalies Connected to HREs. In order to reveal the linkage existing between years with anomalous/suppressed HREs and the circulation weather anomalies during the study period, we performed a composite analysis method for a number of weather parameters and tested their significance with Student's $t$-test in a similar 


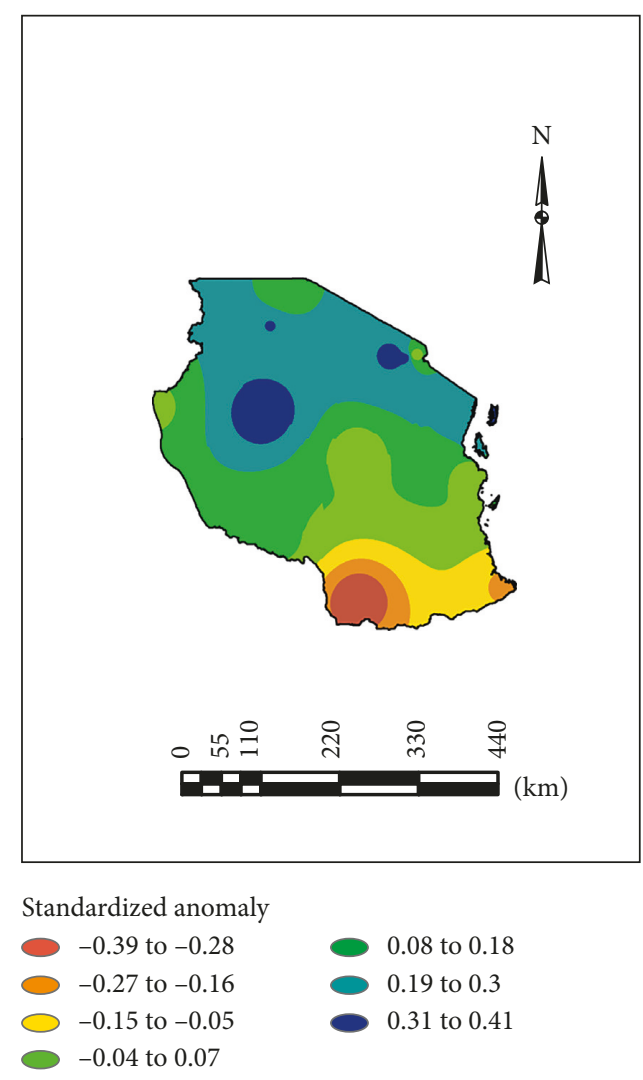

(a)

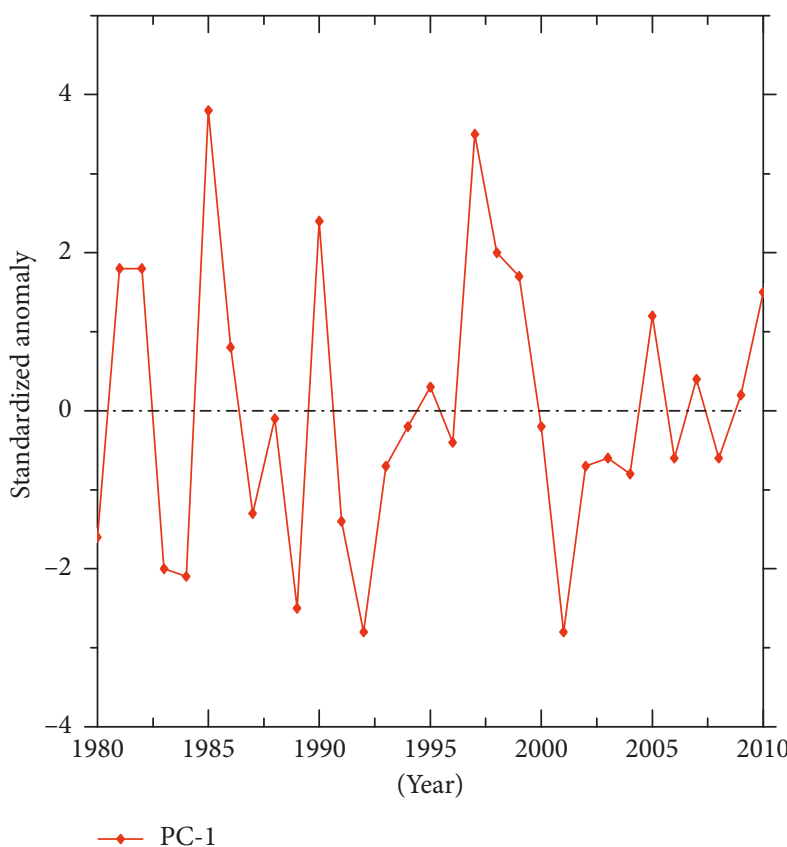

(b)

Figure 4: (a) The spatial pattern of the first EOF mode (EOF-1) and its corresponding PC time series (b) of the mean heavy rainfall during the MAM season based on 1980-2010 climatology.

way as it was done by Indeje et al. [27]. For the composite analysis, years with only strong amplitudes of normalized heavy rainfall departures of greater than +1 (i.e., 1981, 1982, 1985, 1990, 1997, and 1998) were selected as years with anomalous HREs than the normal years. Meanwhile, years with strong amplitudes of normalized heavy rainfall departures of less than -1 (i.e., 1980, 1983, 1984, 1989, 1992, and 2001) were selected as years with suppressed HREs than the normal years. The influence of the upper warm (cold) temperature anomalies to HREs is also demonstrated.

3.4.1. Wind and Moisture Flux Anomalies. Figures 6(a) and 6(b) indicate the spatial pattern of wind vector anomalies at 850 and $200 \mathrm{hPa}$ during anomalous HREs. At $850 \mathrm{hPa}$, the moist and unstable wind from the Congo basin organizes and forms a confluent zone (ITCZ) extending from Congo to NS of the study area (Figure 6(a)). Strengthening of the high-pressure cell over southwestern (SW) Angola is in such a way that it favors its inland movement. The movement relocates the high-pressure cell over the southeastern (SE) Angola (at $21^{\circ} \mathrm{E}$ and $17^{\circ} \mathrm{S}$ ) where it helps to position the meridional arm of the ITCZ over the country and drags the moist laden wind from the Atlantic Ocean towards the western part of the study area converges (i.e., see a red plus sign in Figure 6(a)) with the moist and unstable easterlies/southeasterlies wind from the Indian Ocean and the northwesterly winds originated from the Congo Air basin (CAB). The flow of wind at $200 \mathrm{hPa}$ (Figure 6(b)) is dominated by westerly wind components which persist from low to high levels.

Figure 6(c) marks significant changes where the highpressure cell over SE Angola has shifted towards her coastal belt (to $7^{\circ} \mathrm{E}$ and $19^{\circ} \mathrm{S}$ ). Similarly, there is a dominant strong northeasterly wind component crossing the coastal belt of the study area before decelerating and converge (i.e., see a red plus sign in Figure 6(c)) with southwesterly wind over Zambia. The stronger the northeasterly wind as it passes the country; this implies that the low-level moisture was carried away from the study area to Zambia where the speed is significantly decelerating. There is persistent easterly wind component at $200 \mathrm{hPa}$ (Figure 6(d)). The difference between the mean wind anomalies for the years with anomalous and suppressed HREs was computed in order to show the contrast between the two mean anomalies. Figure 6(e) shows significant westerly wind anomalies sourced from Congo converge over the NS of the study area. It also follows that, repositioning of the high-pressure cell over the SE Angola is in a similar pattern to what is observed during anomalous HREs (Figure 6(a)). There is also persistence of the westerly wind components at $200 \mathrm{hPa}$ (Figure 6(f)) over the study area. Revealing the influence of the low-level moisture transport during the anomalous and suppressed MAM HREs, we focused our analysis on the $850 \mathrm{hPa}$ 

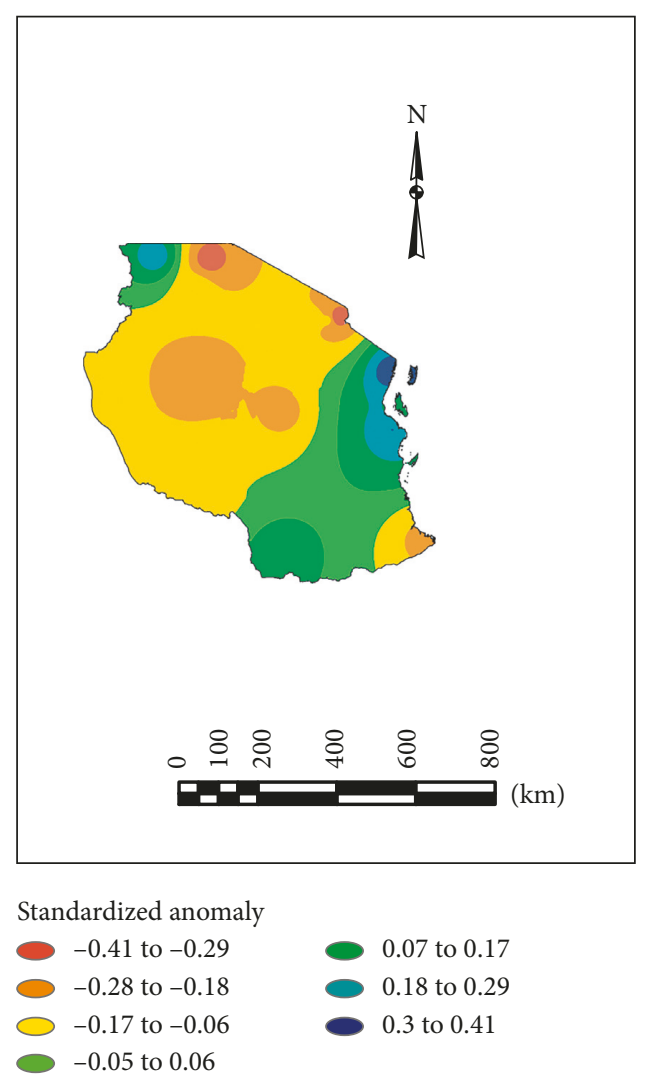

(a)

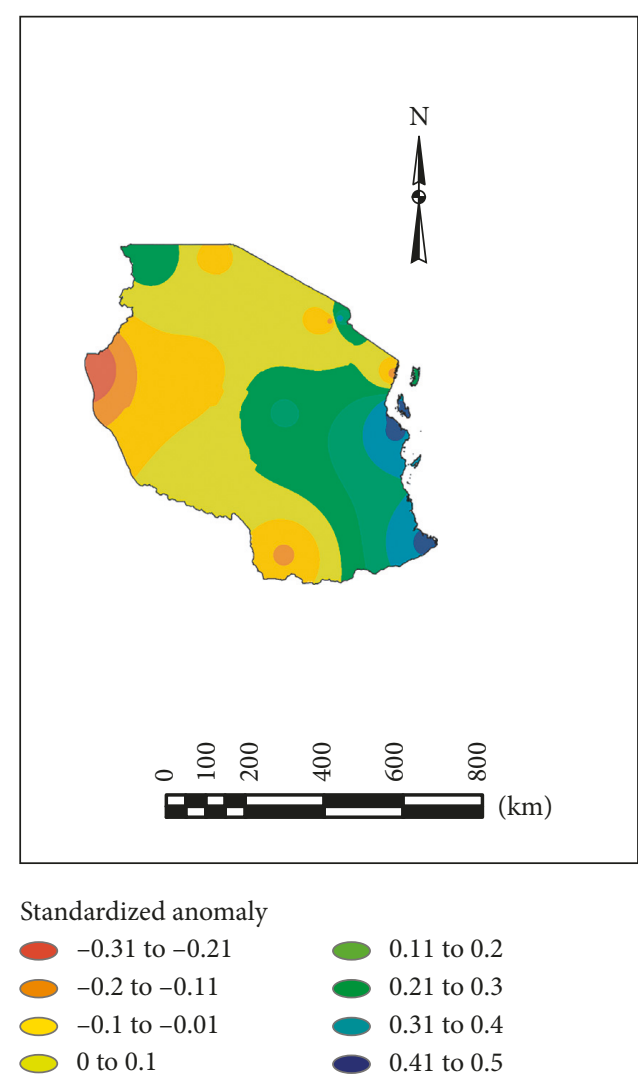

(b)

FIGURE 5: The spatial pattern of (a) the second EOF mode (EOF-2) and (b) the third EOF mode (EOF-3) of the mean heavy rainfall during the MAM season based on 1980-2010 climatology.

level since it is observed to be the most representative behavior for the vertically integrated moisture flux over East Africa [35].

Over the NS of the study area (Figure 7(a)), years with anomalous HREs prevail with the low-level westerly to northwesterly moisture flux transport from Congo while the southern sector is accompanied with insufficient moisture flux. There is a remarkable northerly moisture transport anomaly from Eastern Kenya (i.e., sourced from the maritime tropical Indian Ocean which turns northerly after crossing the Somali coast, Figure 7(a)) towards the NEH and northern coast of the study area where it converges with the westerly/northwesterly moisture anomaly. Since the moisture flux divergence is negative (positive) over the NS (southern sector) in Figure 7(a)), it is therefore consistent with the enhanced convergence (divergence) in moisture flux leading into increased (reduced) amount of HREs within the region (Figures 1(b) and 4(a)). The westerly to northwesterly moisture transport towards the NS confirms how important the moist and unstable air from the Congo basin is so significant for the anomalous heavy rainfall within the area during the MAM season. Similarly, years with suppressed HREs (Figure 7(b)) are accompanied with insufficient influx of moisture over the entire country with an exception to the coastal and extreme southern region of the study area where easterly moisture transport from the tropical Indian Ocean is portrayed. Furthermore, the presence of divergent or weak convergent signals of moisture flux in some areas of the NS (Figure 7(b)) with the persistence of easterly moisture transport anomaly over the coastal and extreme southern sector tallies with suppressed (enhanced) HREs in respective areas (i.e., Figure 5(a)). In general, years with anomalous HREs than normal years are characterized by an organized positioning of the ITCZ on the NS of the study area which facilitated the moist westerly wind anomalies to converge alongside these areas for enhanced convective activities. Also, the western sector of the study area is marked with low-level convergence which could be the main factors increasing the number of HREs over these areas as it was explained in Figure 4(a).

Meanwhile, years with suppressed HREs than normal years were characterized by a shift of the convergence zone away from the western sector of the study area with the confluent pattern/ITCZ over the NS being replaced by shallow easterlies.

3.4.2. Velocity Potential and Divergent Wind Anomalies. Figure 8 represents the composite velocity potential and divergent/convergent wind anomalies for stations over the northern coast and NEH during anomalous HREs. Centers of low (high) velocity potential are associated with divergent outflow (confluent inflow) of winds. Meanwhile, divergence (convergence) in the upper troposphere (i.e., $200 \mathrm{hPa}$ ) is 


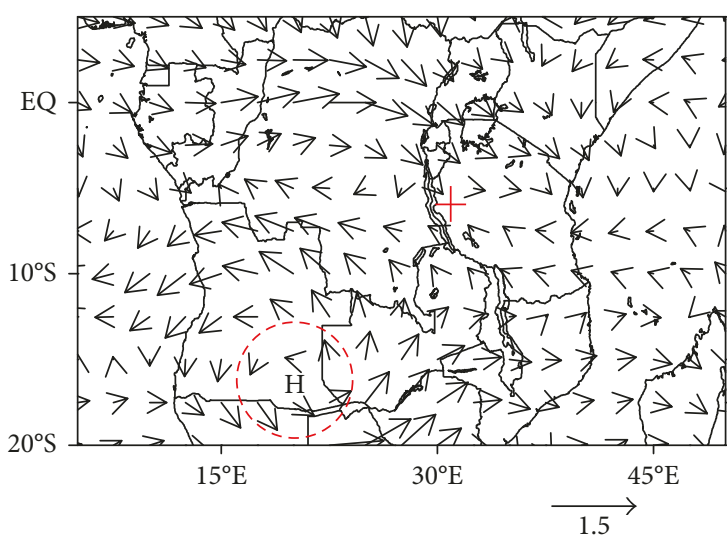

(a)

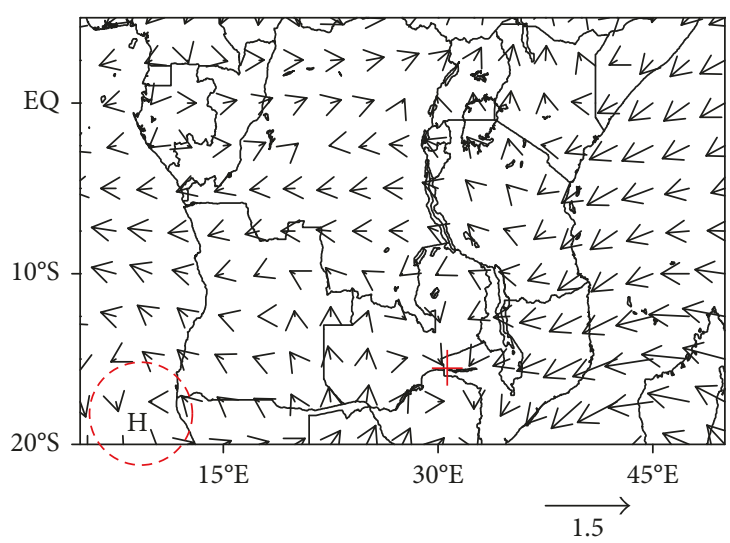

(c)

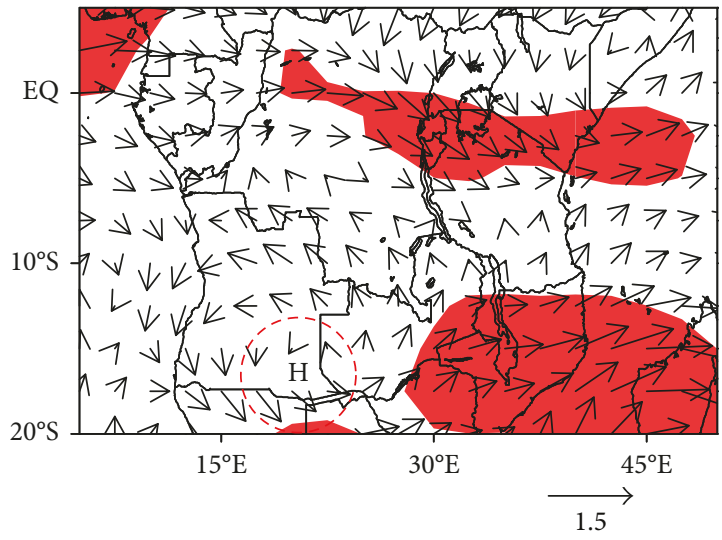

(e)

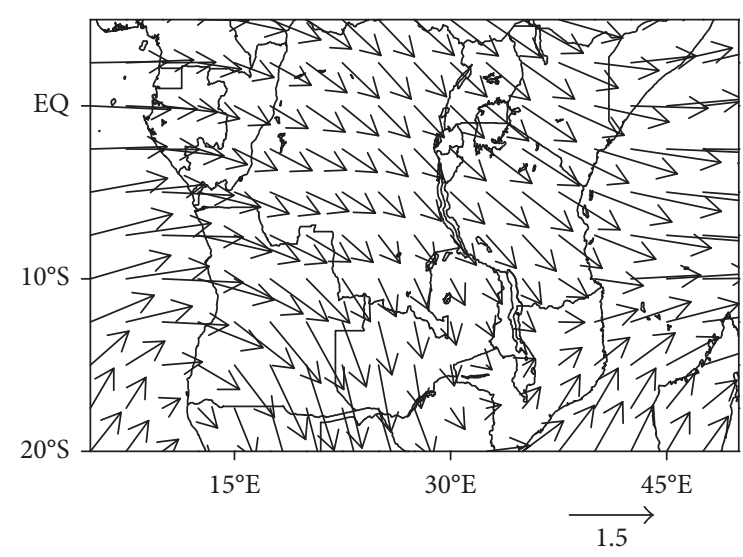

(b)

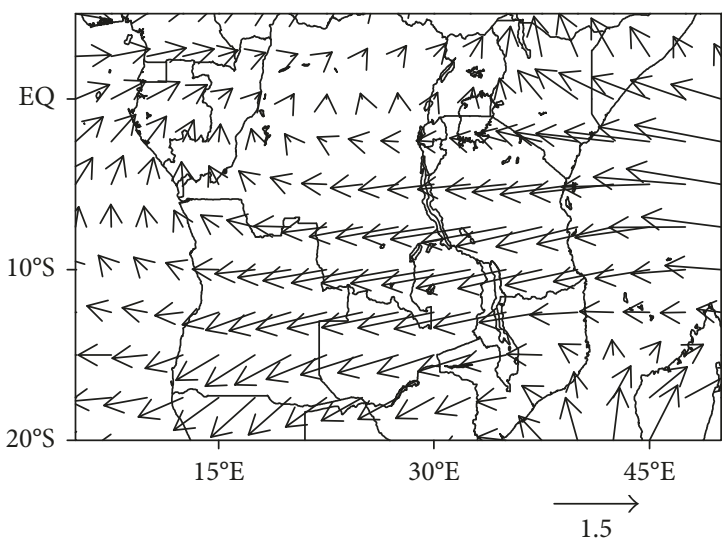

(d)

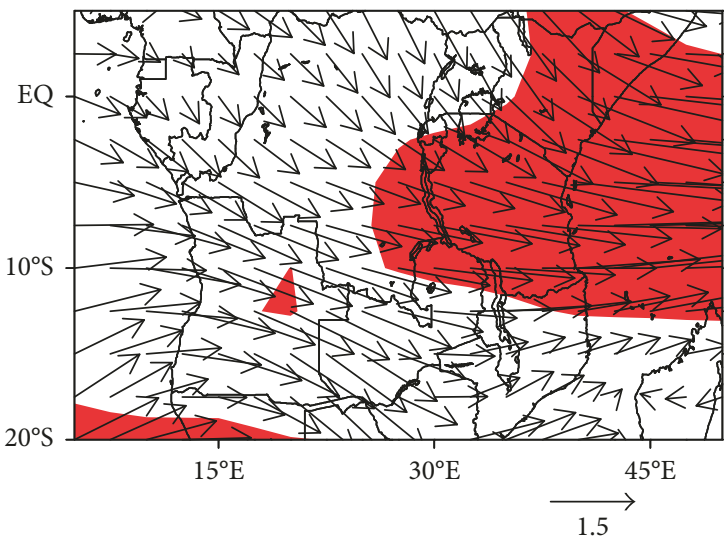

(f)

FIGURE 6: Composite wind vector anomalies for anomalous HREs than normal years at (a) $850 \mathrm{hPa}$ and (b) $200 \mathrm{hPa}$; suppressed HREs than normal years at (c) $850 \mathrm{hPa}$ and (d) $200 \mathrm{hPa}$; the difference between anomalous and suppressed HREs at (e) $850 \mathrm{hPa}$ and (f) $200 \mathrm{hPa}$. Shaded areas are significant regions at $t$-test based on $95 \%$ confidence interval.

accompanied with convergence (divergence) in the lower troposphere. During anomalous HREs (Figure 8(a)), the eastern (western) Atlantic (Indian) is associated with the low tropospheric divergence (convergence). The center of divergence (i.e., at $0^{\circ}$ ) over the eastern Atlantic marks the descending limb of the Atlantic Walker circulation. Notice that, the divergent wind east of the Atlantic center flows eastwards (i.e., with northwesterly dominance, Figure 8(a)) in the lower troposphere and crosses Congo, thereby advecting moist wind towards the study area. The positive velocity potential and wind convergence over the western Indian Ocean (i.e., centered over Eastern Tanzania in Figure 8(a)) coupled with the negative velocity potential and upper tropospheric wind divergence (Figure $8(b)$ ). It therefore reflects the positioning of the ascending limb of the local Indian Ocean Walker circulation over East Africa which enhances convection for anomalous HREs bearing in mind that there is plenty of moisture being advected to the study area. 


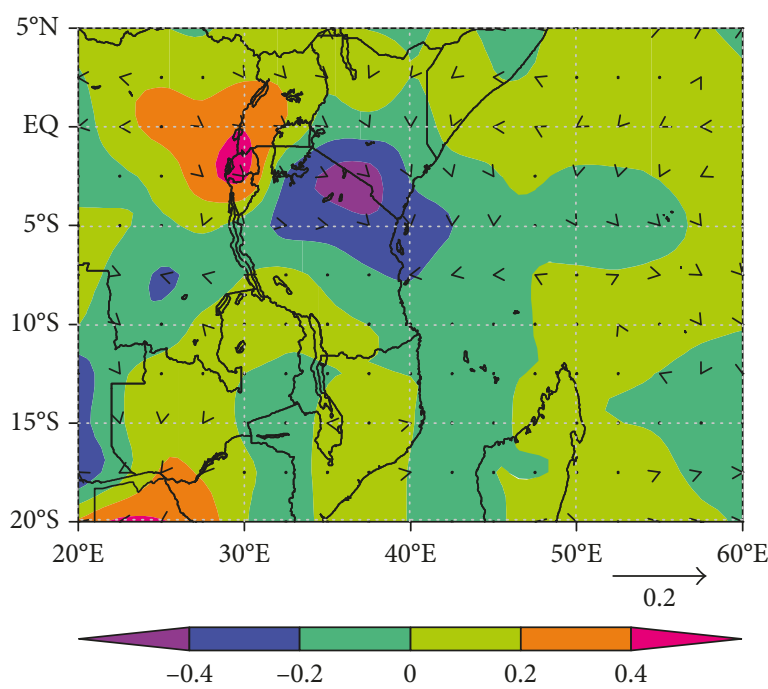

(a)

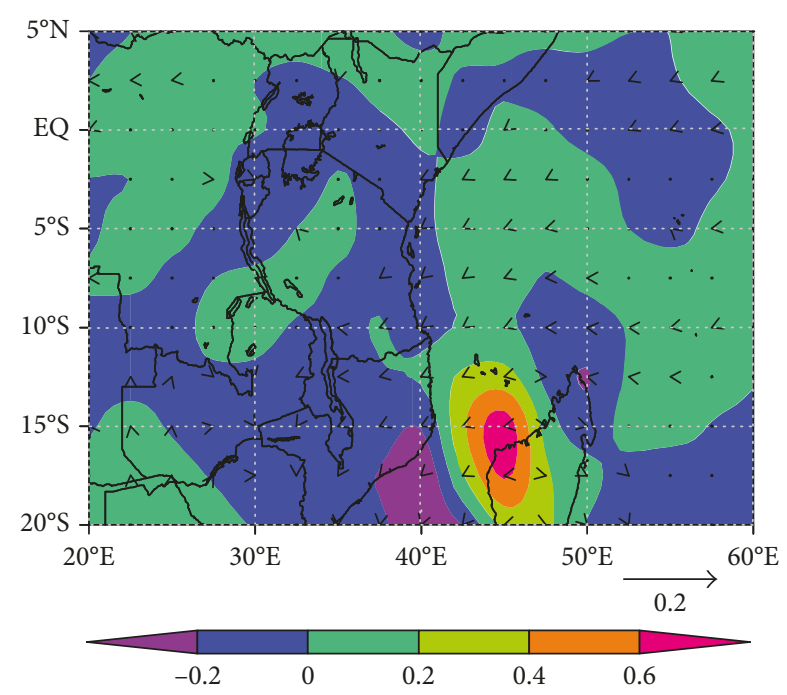

(b)

FIgURE 7: The $850 \mathrm{hPa}$ composite anomaly fields of the moisture flux (vectors) and its divergence (shading) during (a) anomalous HREs and (b) suppressed HREs, where positive and negative shading represents divergence and convergence, respectively. The scale vector corresponds to moisture flux $0.2 \mathrm{~g} / \mathrm{kg} \cdot \mathrm{m} / \mathrm{s}$, and the moisture flux divergence contour interval is $0.2 \times 10^{-8} \mathrm{~g} / \mathrm{kg} / \mathrm{s}$.

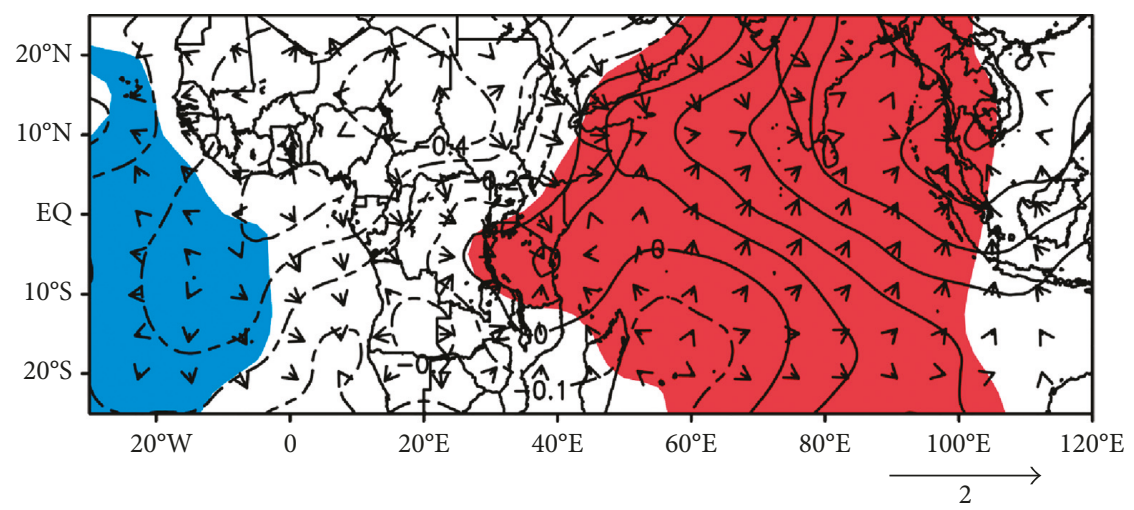

(a)

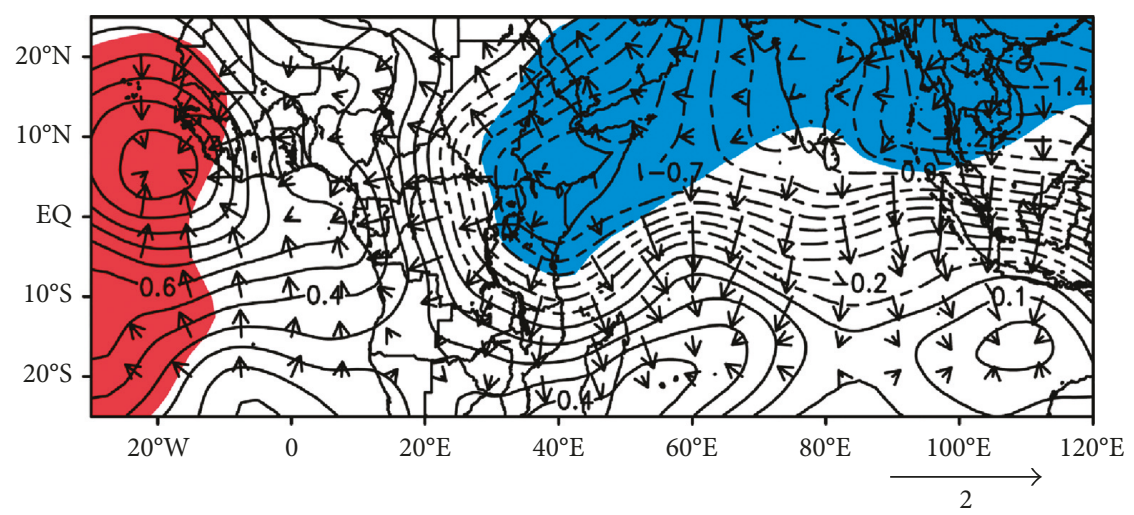

(b)

FIGURE 8: Composite velocity potential and wind divergent anomalies at (a) $850 \mathrm{hPa}$ and (b) $200 \mathrm{hPa}$ for stations over the northern coast and $\mathrm{NEH}$ during anomalous heavy rainfall; units for velocity potential being $1 \times 10^{6} \cdot \mathrm{m}^{2} \mathrm{~s}^{-1}$; divergent wind $\left(\mathrm{s}^{-1}\right)$ while the shading indicates significant areas at $95 \%$ confidence interval. 


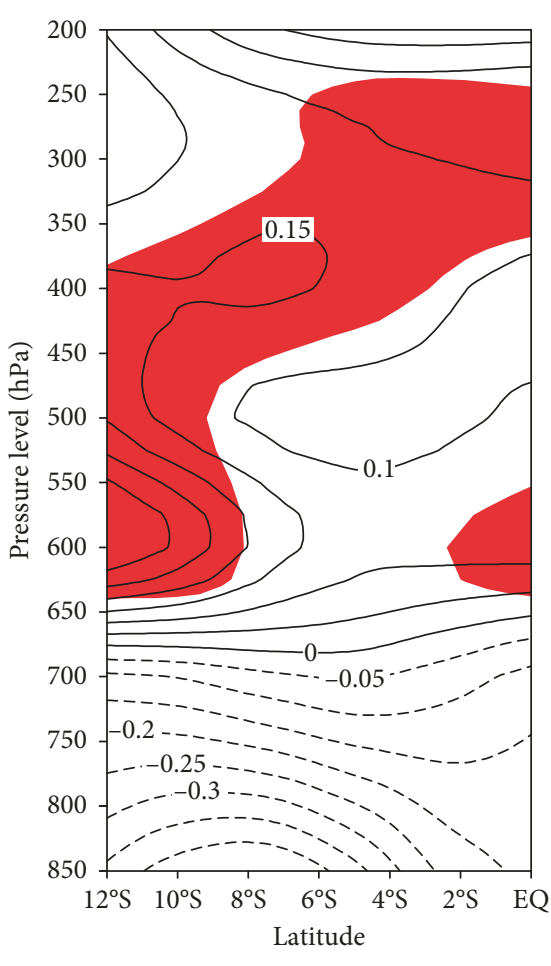

(a)

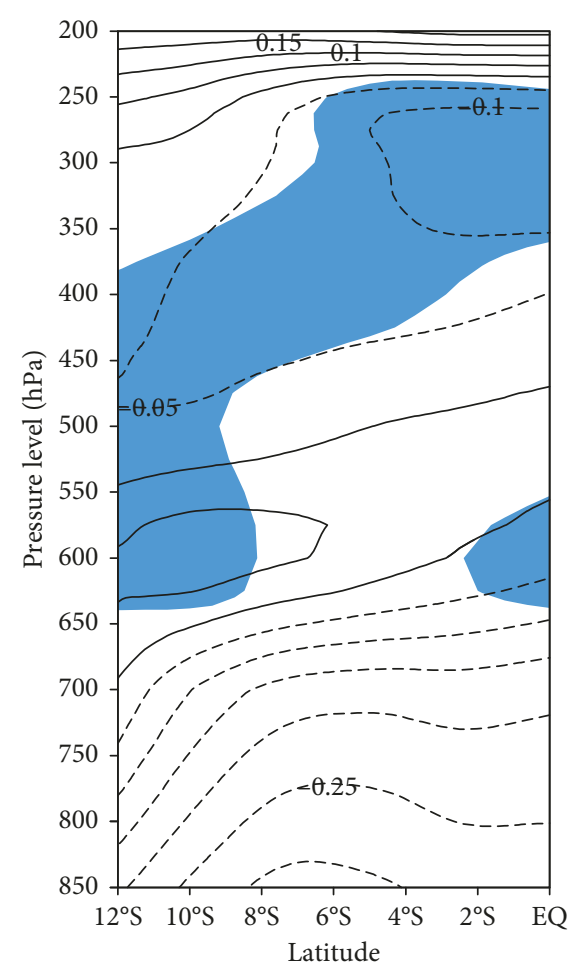

(b)

FIGURE 9: Composite vertical cross section of temperature anomalies along $28^{\circ} \mathrm{E}$ during (a) anomalous and (b) suppressed periods of HREs based on 1980-2010 climatology. Shading indicates significant areas at 95\% confidence interval.

3.4.3. Upper Warm (Cold) Temperature Anomaly. On contrary to the expectations, during intense HREs (Figure $9(\mathrm{a})$ ), we noticed the presence of negative temperature anomalies to the lower levels while the mid- and upper levels are characterized by positive temperature anomalies. An interesting finding in this analysis is the location of the strong positive (negative) temperature anomalies at $300 \mathrm{hPa}$ level (i.e., an upper warm (cold) temperature anomaly) over the NS during anomalous (suppressed) periods of HREs (Figure 9).

In the study of the source of summer heavy rainfall in central Northern China, Sun et al. [51] found that the upper tropospheric warm anomaly cantered at $300 \mathrm{hPa}$ was associated with the westerly (easterly) wind anomalies to the north (south) of the warm center. Under hydrostatic and geostrophic equilibriums, the upper tropospheric warm anomaly contributes to the generation of an anticyclonic (cyclonic) anomaly above (below). But in this study, we realised that the UWTA is accompanied with an eastward increase in the upper zonal wind anomalies (i.e., eastward strengthened in upper westerly wind anomalies) over the study area (see an area marked with dashed rectangle in Figure 10(a)). The results are opposite when the upper cold temperature anomaly (UCTA) is in position where there is the westward increase in the upper zonal wind anomlies (i.e., weakening in upper westerly wind while strengthening in upper easterly wind anomalies). The eastward (westward) increase in the upper zonal wind anomalies over the study area (Figures 10(a) and 10(b)) during anomalous (suppressed) HREs corresponds with an upper-level wind divergence (convergence), thereby accelerating the formation of the cyclonic (anticyclonic) flow in the low level (Figures 10(c) and 10(d)). A detailed discussion on how the UWTA (UCTA) results in an upper-level wind divergence (convergence) are to be followed later.

Rather than looking into detail the structure of the UWTA and UCTA, we broaden our concern on queries arising on how do the duo anomalies influence extreme HREs individually in a dynamical point of view. To answer this question, we consider the use of the thermal wind equation and velocity divergence form of the continuity equation (DFCE) by enumerating the significance of the terms in practical settings. We reasonably owe to use these equations since the horizontal temperature gradient in the thermal wind equation tend to induce the vertical shear to geostrophic wind [52], while the DFCE will help to ascertain reasons on how the vertical shear (i.e., increased/decreased in wind speed) will lead into divergence/convergence, a necessary mechanism for convective processes. According to Holton [52] and taking into account the hydrostatic, geostrophic, geopotential, and ideal gas law equations, the zonal component of geostrophic wind is given as follows:

$$
p \frac{\partial u_{g}}{\partial p}=\frac{\partial u_{g}}{\partial \ln p}=\left(\frac{R}{f} \frac{\partial T}{\partial y}\right)_{p}
$$

Equation (1) illustrates the relationship of the vertical wind shear being the change of the zonal component of geostrophic wind with respect to $\ln p$. 


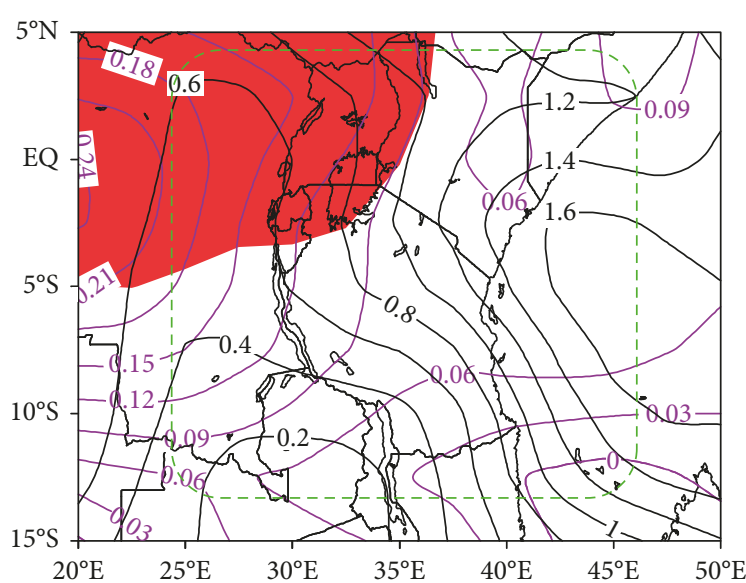

(a)

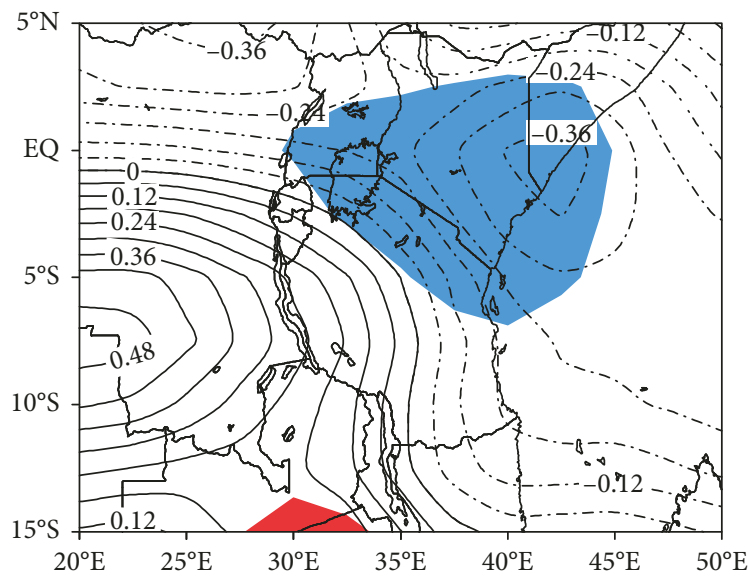

(c)

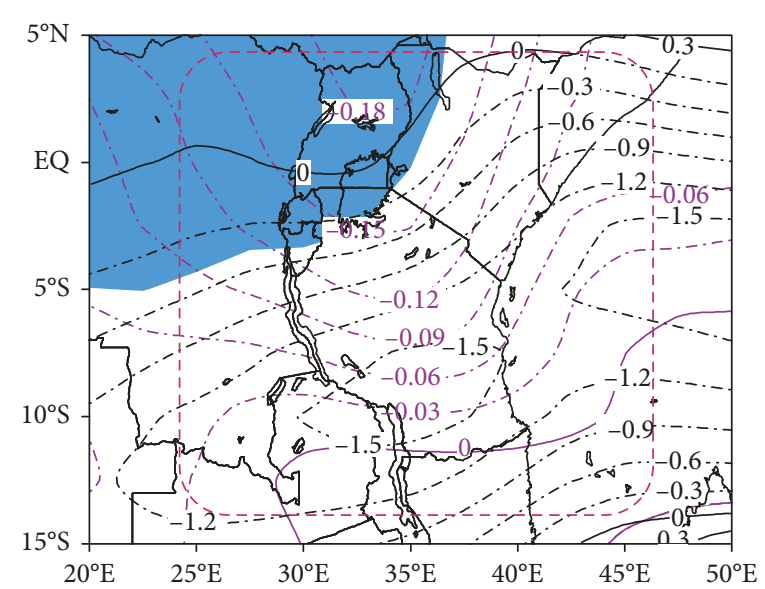

(b)

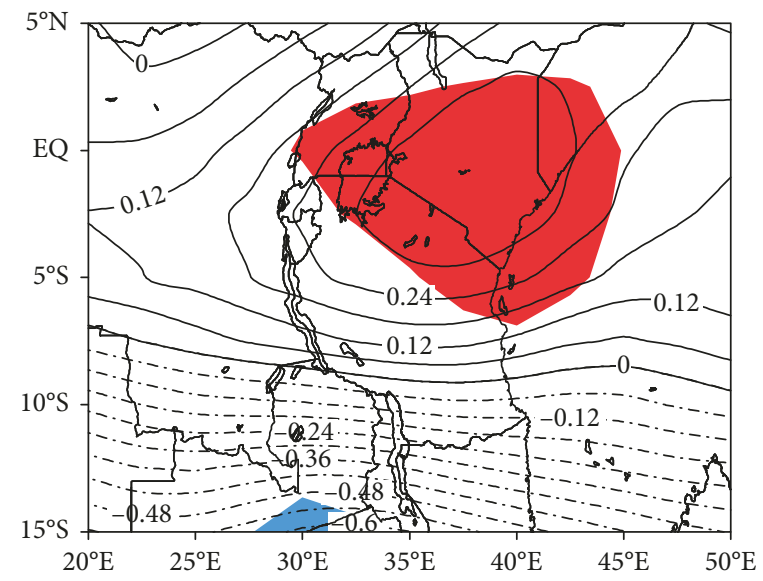

(d)

Figure 10: Composite anomaly distribution fields for the air temperature $\left({ }^{\circ} \mathrm{C}\right.$ ) at $300 \mathrm{hPa}$ level (brown contour) and $200 \mathrm{hPa}$ level zonal components of the wind pattern in $\mathrm{ms}^{-1}$ (black contour) at both (a) and (b); $700 \mathrm{hPa}$ stream function $\left(1 \times 10^{6} \cdot \mathrm{kgs}^{-1}\right)$ at $(\mathrm{c}, \mathrm{d})$ during anomalous ( $a, c)$ and (b, d) during suppressed periods of HREs. The shading (from a-d) denotes significant areas at $95 \%$ confidence interval.

Integrating (1) from $p_{0}$ to $p_{1}$ with condition $p_{0}>p_{1}$, it forms

$$
u_{p_{0}}-u_{p_{1}}=u_{T}=-\frac{R}{f} \frac{\partial \bar{T}}{\partial y} \ln \left(\frac{p_{0}}{p_{1}}\right),
$$

where $\bar{T}$ is the mean temperature in the layer between isobaric levels $p_{0}$ and $p_{1}, f$ is the Coriolis parameter, $u_{T}$ is the zonal component of the thermal wind, and $u_{p_{0}}-u_{p_{1}}$ is the change in the zonal component of geostrophic wind between $p_{0}$ and $p_{1}$. Equation (2) states that the change in geostrophic wind between two isobaric levels $p_{0}$ and $p_{1}$ is directly related to the horizontal layer mean temperature gradient (HMTG), $\partial \bar{T} / \partial y$, between respective levels and therefore a good diagnostic tool in checking the analysis of the observed wind in these levels.

Substituting $u_{p_{0}}, u_{p_{1}}$, and $\partial \bar{T} / \partial y$ from (2) with the anomaly fields of $u_{p_{1}}^{\prime}, u_{p_{0}}^{\prime}$, and $\partial \bar{T}^{\prime} / \partial y$, respectively, the equation becomes

$$
\Delta u^{\prime}=u_{p_{1}}^{\prime}-u_{p_{0}}^{\prime}=\frac{R}{f} \frac{\partial \bar{T}^{\prime}}{\partial y} \ln \left(\frac{p_{0}}{p_{1}}\right)
$$

where $u_{p_{0}}^{\prime}$ is the zonal geostrophic wind anomaly of the lower isobaric level, $u_{p_{1}}^{\prime}$ is the zonal geostrophic wind anomaly of the upper isobaric level, $\partial \bar{T}^{\prime} / \partial y$ is HMTG anomaly between $p_{0}$ and $p_{1}$ isobaric levels, and $\Delta u^{\prime}$ is the difference in the zonal geostrophic wind anomalies between $p_{0}$ and $p_{1}$ isobaric levels. It should be noted that anomaly fields in (3) are computed as the departure from the 6-year mean of anomalous (suppressed) HREs. Equation (3) gives an expression that the rise (fall) of HMTG anomaly between $p_{0}$ and $p_{1}$ layer increases (decreases) the differences in the zonal geostrophic wind anomalies between the respective isobaric levels, $\uparrow \Delta u^{\prime}\left(\downarrow \Delta u^{\prime}\right)$, by which its effects are towards increasing (decreasing) the zonal geostrophic wind anomalies of the upper isobaric level, $\uparrow u_{p_{1}}^{\prime}\left(\downarrow u_{p_{1}}^{\prime}\right)$.

The practical quantification of (3) was carried out to investigate the influence of the mid- to upper-level HMTG anomalies (i.e., $600-300 \mathrm{hPa}$ and $600-200 \mathrm{hPa}$ isobaric levels, Figure 9) and its corresponding influence on the differences in the zonal geostrophic wind anomalies within the layers during anomalous periods of HREs. Figure 11(a) represents the spatial distribution of the $600-300 \mathrm{hPa}$ average layer temperature anomalies during anomalous periods of HREs. To have a better knowledge on how the UWTA enhances anomalous HREs over the NS of the study area, we 


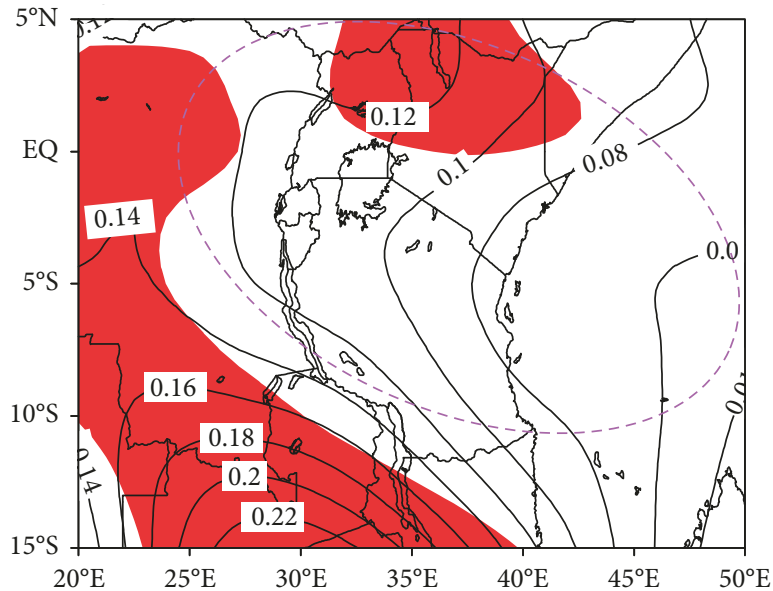

(a)

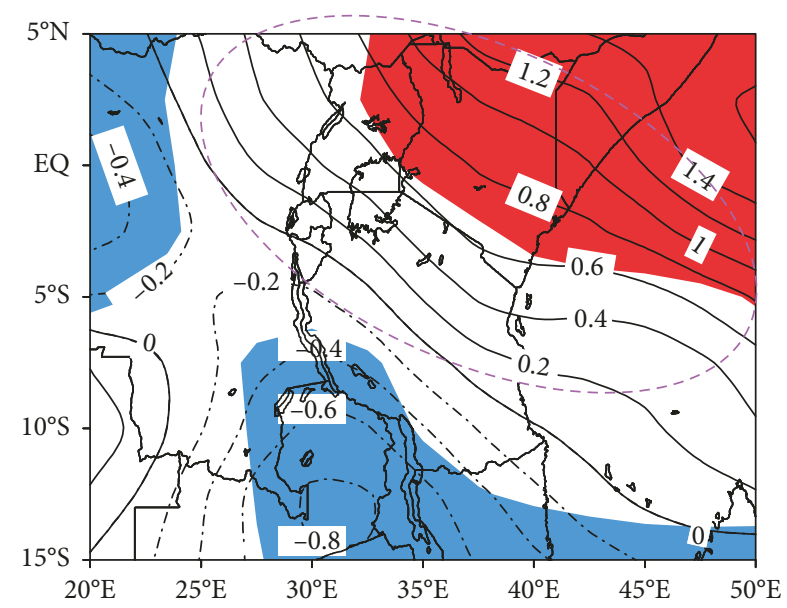

(b)

Figure 11: (a) 600-300 hPa average layer temperature anomalies (contour interval $0.02^{\circ} \mathrm{C}$ ) and (b) the difference in zonal wind anomalies between 600 and $300 \mathrm{hPa}$ levels (contour interval $0.2 \mathrm{~ms}^{-1}$ ) during anomalous periods of HREs. Shading represents areas at $95 \%$ confidence level.

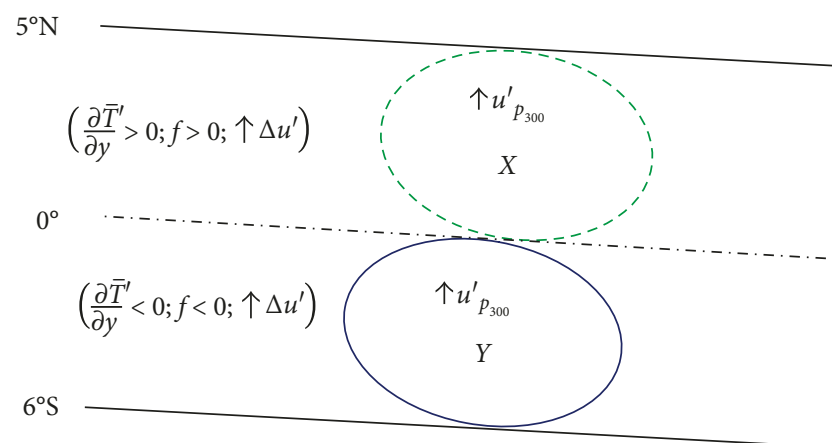

FIGURE 12: Schematic diagram for the spatial distribution of the horizontal mean layer meridional temperature gradient (HMTG) anomalies within $600-300 \mathrm{hPa}$ layer over an area marked with a dashed solid line elliptic circle in Figure 11(a) during anomalous periods of HREs. Schemes $X$ and $Y$ are the latitudinal cross section through the Equator for an area marked with a dashed elliptic circle (Figure 11(a)).

carried out a schematic analysis on the area marked with a dashed elliptic circle (Figure 11(a)). A latitudinal cross section through the Equator of an area marked with a dashed elliptic circle (Figure 11(a)) deemed the positioning of two areas one the above (i.e., scheme $X$ ) and the other below (i.e., scheme $Y$ ) the Equator (Figure 12). Following the decrease in the mean layer $(600-300 \mathrm{hPa})$ temperature anomalies from the higher to lower latitudes in scheme $X$ (i.e., $5^{\circ} \mathrm{N}$ to $0^{\circ}$ ), it makes the area within the scheme being in favor of positive HMTG anomaly $\left(\partial \bar{T}^{\prime} / \partial y>0\right)$. Scheme $Y$ defines the area with negative HMTG anomaly with latitude $\left(\partial \bar{T}^{\prime} / \partial y<0\right)$ bearing in mind that the mean layer $(600-$ $300 \mathrm{hPa}$ ) temperature anomalies increase from the low to high latitudes (i.e., $0^{\circ} \mathrm{N}$ to $6^{\circ} \mathrm{S}$ ). Making use of (3) and taking into account the respective HMTG anomalies and Coriolis parameter in scheme $X(f>0)$ and scheme $Y(f<0)$, both schemes portray the increase in the difference of the zonal geostrophic wind anomaly $\left(\uparrow \Delta u^{\prime}\right)$. The increase in the difference of the zonal geostrophic wind anomaly corresponds with the increase in the $300 \mathrm{hPa}$ zonal geostrophic wind anomaly in respective schemes (Figure 12). Since the schematic analysis in schemes $X$ and $Y$ are the subsets of an area enclosed with a dashed elliptic circle in Figure 11(a), it is worthwhile to note that the NS of the study area (i.e., dashed elliptic circle in Figure 11(b)) is in favor of an eastward increase in the upper-level (in hereafter $300 \mathrm{hPa}$ level) zonal geostrophic wind anomaly (i.e., eastward strengthening in the upper westerly wind anomalies).

Assessing the way on how the increase (decrease) of the upper-level zonal wind anomalies in (3) influences the upperlevel divergence (convergence), we diagnose the following DFCE:

$$
\frac{1}{\rho} \frac{D \rho}{D t}+\nabla \cdot \mathbf{U}=0
$$

where $\rho$ is the density, $\mathbf{U}$ is the three dimension velocity vector, $t$ is time, and $\boldsymbol{\nabla}$ is the Laplacian operator. However, the horizontal divergence anomaly, $\boldsymbol{\nabla}_{\mathbf{H}} \cdot \Delta \mathbf{U}^{\prime}$, in (4) can be expressed as follows:

$$
-\nabla_{\mathbf{H}} \cdot \mathbf{U}^{\prime}=-\left(\frac{\partial u^{\prime}}{\partial x}+\frac{\partial v^{\prime}}{\partial y}\right)=\frac{\partial w^{\prime}}{\partial z},
$$

where $w^{\prime}$ is the vertical velocity anomaly. For detailed expansion and discussion of the DFCE, refer to the study by Holton [52].

The difference in zonal wind anomalies between 600 and $300 \mathrm{hPa}$ levels in Figure 11(b) shows the longitudinal (eastward) increase in the differences with more positive anomalies towards the NS of the study area. The eastward increase in the differences tallies with that of the $300 \mathrm{hPa}$ zonal wind anomalies (i.e., figure not included) particularly over the NS. Taking the longitudinal cross section of the $300 \mathrm{hPa}$ zonal wind anomaly for an area over the NS, it shows positive zonal wind gradient anomaly $\left(\partial u^{\prime} / \partial x>0\right)$ over the NS following an eastward increase of the $300 \mathrm{hPa}$ 


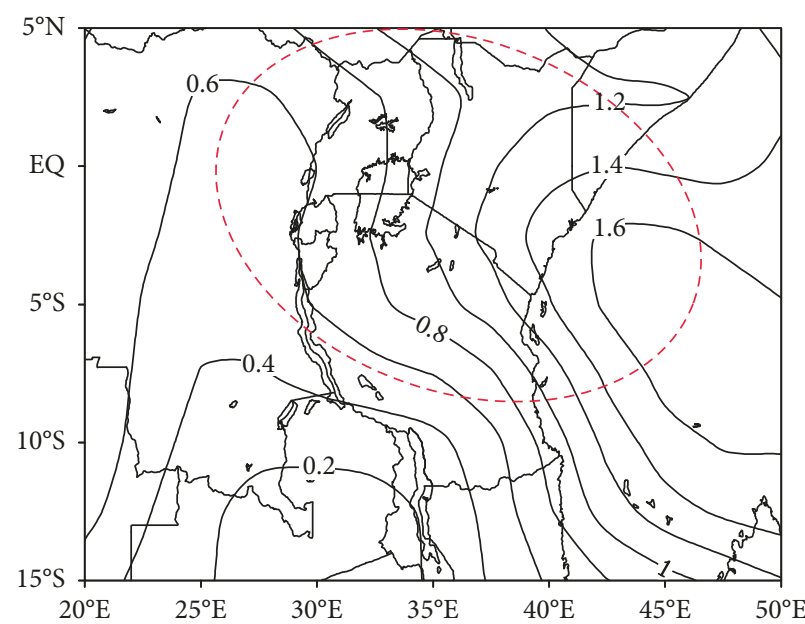

(a)

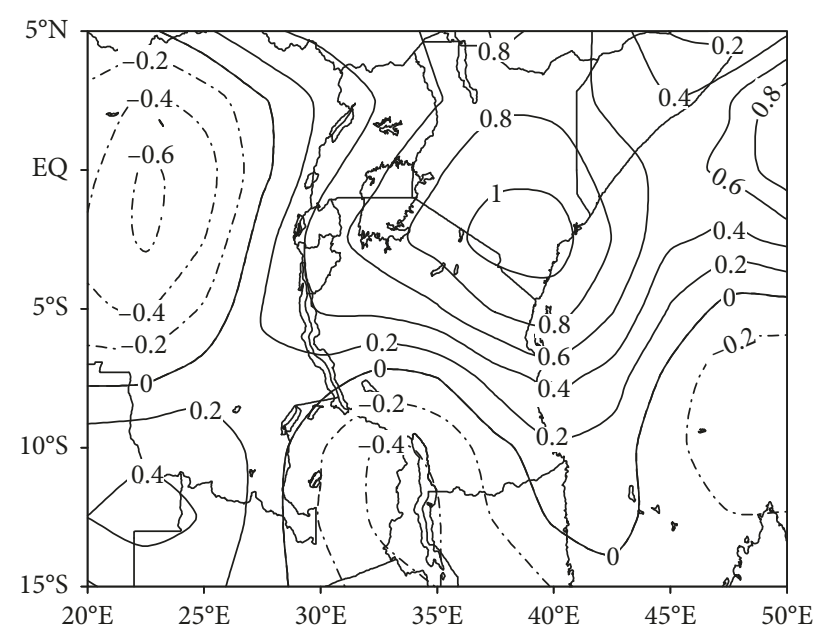

(b)

FIGURE 13: A spatial distribution pattern of the (a) zonal wind anomaly fields in $\mathrm{ms}^{-1}$ and (b) horizontal wind divergence anomaly fields (contour intervals $0.2 \times 10^{-6} \cdot \mathrm{s}^{-1}$ ) at $200 \mathrm{hPa}$ isobaric level during anomalous HREs based on 1980-2010 climatology.

zonal wind anomalies. With the use of (5) while ignoring the component of the meridional gradient wind anomaly, it therefore suggests that the area enclosed by a dashed elliptic circle in Figure 11(a) is under the dominance of the upperlevel horizontal wind divergence since the divergence term is greater than zero $\left(\boldsymbol{\nabla}_{\mathbf{H}} \cdot \mathbf{U}^{\prime}>0\right)$.

When the $600-200 \mathrm{hPa}$ levels were involved in the analysis (figures not included), its HMTG anomalies and corresponding differences in the zonal geostrophic wind anomalies figured an agreement with the results represented in schemes $X$ and $Y$. For instance, Figure 13(a) shows the $200 \mathrm{hPa}$ wind anomalies during anomalous HREs with an eastward increase in the zonal wind anomalies over the NS of the study area (i.e., see an elliptical circle in Figure 13(a)). The longitudinal cross section of the area within the dashed elliptical circle in Figure 13(a) suggests the presence of positive gradient of the zonal wind anomaly $\left(\partial u^{\prime} / \partial x>0\right)$ which favors an upper-level divergence (Figure 13(b)) since the divergence term remains positive $\left(\nabla_{\mathbf{H}} \cdot \mathbf{U}^{\prime}>0\right)$. The strong upper-level wind divergence centered at $2^{\circ} \mathrm{S}$ and $38^{\circ} \mathrm{E}$ (Figure 13(b)) extending over the coastal belt and NS of the country acts as the primer in accelerating the vertical ascent (Figure 14) and deepening the low pressure at low level (Figure 10(c)), an important mechanism in convective instability and HREs formation in the locality.

It is clear from Figure 9 that strong positive and negative coefficients of temperature anomalies are positioned at $300 \mathrm{hPa}$, making this level the most likely contributor to the HMTG anomalies within the layer (i.e., $600-300 \mathrm{hPa}$ and 600-200 hPa levels). We noticed that the rise and fall of temperature anomalies at $300 \mathrm{hPa}$ has a pronounced effect not only on the $200 \mathrm{hPa}$ zonal geostrophic wind speed anomalies but also on the wind direction.

\section{Summary and Conclusion}

In this study, we investigated the spatial and temporal distribution of HREs together with the impaction of the

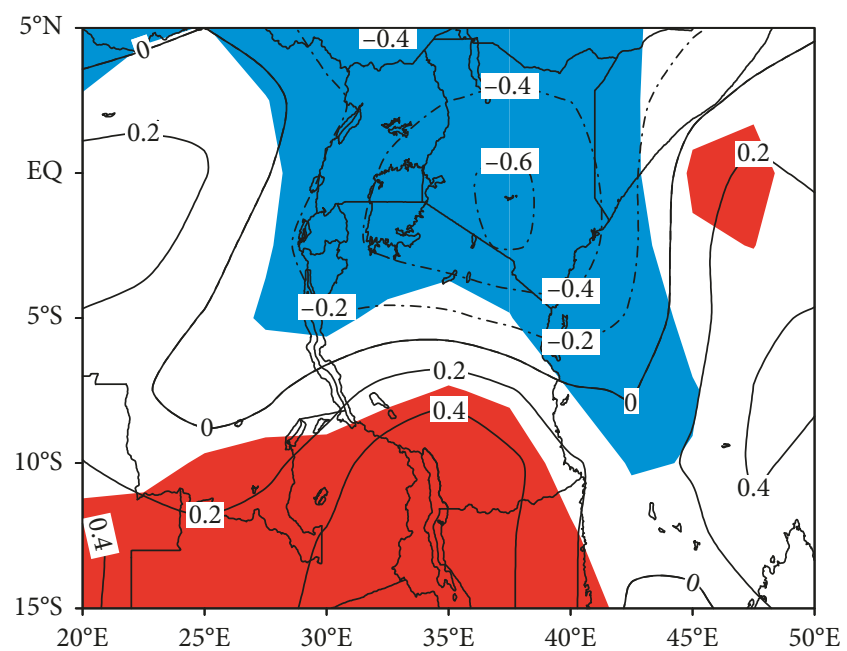

FIGURE 14: Composite spatial pattern for the $200 \mathrm{hPa}$ vertical velocity anomaly (contour intervals $0.2 \times 10^{-2} \cdot \mathrm{Pas}^{-1}$ ) field during anomalous HREs based on 1980-2010 climatology. Negative values indicate upward motion, while shading represents significant areas at $95 \%$ confidence interval.

UWTA among other circulation anomalies during the MAM rainfall season in Tanzania based on 1980-2010 climatology. A total of 822 HREs were revealed from sixteen (16) synoptic stations involved in the analysis. HREs are found to be concentrated over the NS, and along the coastal belt, the extreme concentration was mainly to the western Lake Victoria basin (i.e., Bukoba) and over extreme northern coast (i.e., Tanga, Zanzibar, and Pemba).

We noted that the higher number of HREs were also found to enhance the total MAM rainfall over respective areas significantly and therefore subjected to the risks of flooding events especially during April (at most) and May while March being the least vulnerable month to the risks of HREs. An overall trend of heavy rainfall over the country during the period of study shows the majority of the stations 
are with positive (increasing) trend either being significant at $95 \%$ confidence interval but without changing points or with changing points (abrupt changes), while insignificant at $95 \%$ confidence interval.

However, the study examined circulation patterns that were linked to anomalous (suppressed) HREs during MAM of 1980-2010 climatology. Years with strong amplitude of normalized heavy rainfall departures of greater than +1 and less than -1 of the standard deviation were used and classified as years with anomalous and suppressed HREs than normal years, respectively. The observed circulation features indicate that anomalous heavy rainfall over the NS of the country (i.e., Kigoma, Tabora, Lake Victoria basin, Tanga, Moshi, KIA, Arusha, Pemba, and Zanzibar) were related to low-level westerly convergence, enhanced low-level moisture flux convergence, and pronounced uplift motion.

During the period of anomalous HREs, the ITCZ was well positioned over the NS of the country while pulling the moist and unstable westerlies from the Congo basin towards the NS where it converges at low levels. The low-level influx of moisture was an input due to strengthening and an inland movement of the high-pressure cell over the Angola coast. The strengthening/positioning (at $21^{\circ} \mathrm{E}$ and $17^{\circ} \mathrm{S}$ ) of the said high-pressure cell helps to position the meridional arm of the ITCZ over the study area and the transfer the moist southwesterly winds from the Atlantic and western areas towards the country where it converges with the moist easterlies from Indian Ocean and westerlies/northwesterlies from $\mathrm{CAB}$ to favor pronounced convection over the western part of the study region.

Furthermore, the composite velocity potential anomalies indicate the position of the ascending limb of the Walker circulation type centered over Tanzania. Overall, a strong uplift in the NS is accompanied with the fetch of the lowlevel moisture flux from Congo basin and tropical Indian Ocean where it converges and favors a pronounced convection leading to anomalous heavy falls. Since the UWTA is associated with the formation of the upper-level wind divergence, low at low levels, and strengthened upper-level westerlies, it is strongly thought to induce deep convection over the NS leading into increased HREs. Making use of the thermal wind equation and the velocity divergent form of continuity equation (DFCE), we found that the UWTA results into an upper-level horizontal wind divergence which significantly accelerate vertical ascent, deepening the surface low pressure for an enhanced convective process and HREs formation.

We also found that the circulation patterns induced by the UCTA are in opposite to those of the UWTA; the implication is that the UCTA is towards suppressing HREs. The study examined the patterns involved in periods of suppressed HREs and manages to observe a shift of the low-level convergence away from the study area while being placed over Zambia. The reason for the shift in the pattern is the weakening and retarding back (to $7^{\circ} \mathrm{E}$ and $19^{\circ} \mathrm{S}$ ) of the highpressure cell over the Angola coast coupled with strong northeasterly winds crossing the coastal belt of the study area and finally converging over Zambia to favor convection over the particular area. The presence of divergent or weak convergent signals of moisture flux in some areas of the NS was the key factor to reveal the deficit of HREs over the NS of the country.

\section{Conflicts of Interest}

The authors declare that there are no conflicts of interest regarding the publication of this paper.

\section{Acknowledgments}

The authors wish to express their sincere thanks to NCEP/NCAR and the director general of TMA, Dr. Agnes L. Kijazi, for making reanalysis and daily observation rainfall data available. The first author is grateful to Nanjing University of Information Sciences and Technology (NUIST) for granting him the fellowship to pursue his Ph.D. studies, without which this work could not have been possible. The work described in this paper was supported by National Natural Science Foundation of China (41475088) and National Science and Technology Support Program of China (2015BAC03B02).

\section{References}

[1] CRED EM-DAT, The OFDA/CRED-International Disaster Database, Université Catholique de Louvain, Brussels, Belgium, 2015.

[2] S. P. Wani, T. K. Sreedevi, J. Rockström, and Y. S. Ramakrishna, Rainfed agriculture-past trends and future prospects, in Rainfed Agriculture: Unlocking the Potential, Comprehensive Assessment of Water Management in Agriculture Series: 7, S. P. Wani, J. Rockström, and T. Oweis, Eds., pp. 1-35, CABI, Wallingford, UK, 2009, ISBN 9781845933890.

[3] R. D. Stern and P. J. M. Cooper, "Assessing climate risk and climate change using rainfall data-a case study from Zambia," Experimental Agriculture, vol. 47, no. 2, pp. 241-266, 2011.

[4] P. S. Chu, Y. R. Chen, and T. A. Schroeder, "Changes in precipitation extremes in the Hawaiian Islands in a warming climate," Journal of Climate, vol. 23, no. 18, pp. 4881-4900, 2010.

[5] R. Y. and W. S. J. Li, "Calculation and analysis of the thresholds of hourly extreme precipitation in mainland China (in Chinese)," Torrential Rain Disasters, vol. 32, pp. 11-16, 2013.

[6] W. Sun, J. Li, and R. Yu, "Corresponding relation between warm season precipitation extremes and surface air temperature in South China," Advances in Climate Change Research, vol. 9, pp. 96-101, 2013.

[7] P. Zhai, X. Zhang, H. Wan, and X. Pan, "Trends in total precipitation and frequency of daily precipitation extremes over China," Journal of Climate, vol. 18, no. 7, pp. 1096-1108, 2005.

[8] Y. Ding, Advanced Synoptic Meteorology in Chinese, China Meteorological Press, Beijing, China, 2nd edition, 2005.

[9] Y. Wang and L. Zhou, "Observed trends in extreme precipitation events in China during 1961-2001 and the associated changes in large-scale circulation," Geophysical Research Letters, vol. 32, no. 9, pp. 1-4, 2005.

[10] Q. You, S. Kang, E. Aguilar et al., "Changes in daily climate extremes in China and their connection to the large scale atmospheric circulation during 1961-2003," Climate Dynamics, vol. 36, no. 11-12, pp. 2399-2417, 2011.

[11] Q. Zhang, C. Y. Xu, Z. Zhang, Y. D. Chen, C. Ling Liu, and H. Lin, "Spatial and temporal variability of precipitation 
maxima during 1960-2005 in the Yangtze River basin and possible association with large-scale circulation," Journal of Hydrology, vol. 353, no. 3-4, pp. 215-227, 2008.

[12] P. Camberlin and N. Philippon, "The East African MarchMay rainy season: associated atmospheric dynamics and predictability over the 1968-97 period," Journal of Climate, vol. 15, no. 9, pp. 1002-1019, 2002.

[13] A. L. Kijazi and C. J. C. Reason, "Intra-seasonal variability over the northeastern highlands of Tanzania," International Journal of Climatology, vol. 32, no. 6, pp. 874-887, 2012.

[14] S. E. Nicholson, "A review of climate dynamics and climate variability in Eastern Africa," in The Limnology, Climatology and Paleoclimatology of the East African Lakes, T. C. Johnson and E. O. Odada, Eds., Gordon and Breach, Toronto, Canada, 1996.

[15] M. J. McHugh and J. C. Rogers, "North Atlantic oscillation influence on precipitation variability around the Southeast African convergence zone," Journal of Climate, vol. 14, no. 17, pp. 3631-3642, 2001.

[16] M. J. Mchugh, "Near-surface zonal flow and east African precipitation receipt during austral summer," Journal of Climate, vol. 17, no. 20, pp. 4070-4079, 2004.

[17] R. E. Okoola, "A diagnostic study of the eastern Africa monsoon circulation during the Northern Hemisphere spring season," International Journal of Climatology, vol. 19, no. 2, pp. 143-168, 1999.

[18] C. C. Mutai and M. N. Ward, "East African rainfall and the tropical circulation/convection on intraseasonal to interannual timescales," Journal of Climate, vol. 13, no. 22, pp. 3915-3939, 2000.

[19] P. Camberlin, S. Janicot, and I. Poccard, "Seasonality and atmospheric dynamics of the teleconnection between African rainfall and tropical sea-surface temperature: Atlantic vs. ENSO," International Journal of Climatology, vol. 21, no. 8, pp. 973-1005, 2001.

[20] H. Wang and R. Fu, "The influence of Amazon rainfall on the Atlantic ITCZ through convectively coupled Kelvin waves," Journal of Climate, vol. 20, no. 7, pp. 1188-1201, 2007.

[21] A. J. Matthews, "Intraseasonal variability over tropical Africa during northern summer," Journal of Climate, vol. 17, no. 12, pp. 2427-2440, 2004.

[22] F. Mounier, S. Janicot, and G. N. Kiladis, "The west African monsoon dynamics. Part III: the quasi-biweekly zonal dipole," Journal of Climate, vol. 21, no. 9, pp. 1911-1928, 2008.

[23] M. Wheeler, G. N. Kiladis, and P. J. Webster, "Large-scale dynamical fields associated with convectively coupled equatorial waves," Journal of the Atmospheric Sciences, vol. 57, no. 5, pp. 613-640, 2000.

[24] J. E. Janowiak, "An investigation of interannual rainfall variability in Africa," Journal of Climate, vol. 1, no. 3, pp. 240-255, 1988.

[25] L. J. Ogallo, "Relationships between seasonal rainfall in East Africa and the southern oscillation," Journal of Climatology, vol. 8 , no. 1 , pp. 31-43, 1988.

[26] S. E. Nicholson and J. Kim, "The relationship of the El-NinoSouthern Oscillation to African rainfall," International Journal of Climatology, vol. 17, no. 2, pp. 117-135, 1997.

[27] M. Indeje, F. H. M. Semazzi, and L. J. Ogallo, "ENSO signals in East African rainfall seasons," International Journal of Climatology, vol. 20, no. 1, pp. 19-46, 2000.

[28] A. L. Kijazi and C. J. C. Reason, "Relationships between intraseasonal rainfall variability of coastal Tanzania and ENSO," Theoretical and Applied Climatology, vol. 82, no. 3-4, pp. 153-176, 2005.
[29] L. J. Ogallo, J. E. Janowiak, and M. S. Halpert, "Teleconnection between seasonal rainfall over East Africa and global sea surface temperature anomalies," Journal of the Meteorological Society of Japan, vol. 66, no. 6, pp. 807-822, 1988.

[30] S. Hastenrath, A. Nicklis, and L. Greischar, "Atmospherichydrospheric mechanisms of climate anomalies in the western equatorial Indian Ocean," Journal of Geophysical Research, vol. 98, no. 11, p. 20219, 1993.

[31] J. Phillips and B. McIntyre, "ENSO and interannual rainfall variability in Uganda: implications for agricultural management," International Journal of Climatology, vol. 20, no. 2, pp. 171-182, 2000.

[32] D. P. Rowell, J. M. Ininda, and M. N. Ward, "The impact of global sea surface temperature patterns on seasonal rainfall in East Africa," in Proceedings of the International Conference on Monsoon Variability and Prediction, pp. 666-672, Trieste, Italy, May 1994.

[33] R. E. Okoola, "Westwards moving disturbances in the Southwest Indian Ocean," Meteorology and Atmospheric Physics, vol. 41, no. 1, pp. 35-44, 1989.

[34] R. C. Hills, "The structure of the inter-tropical convergence zone in equatorial Africa and its relationship to East African rainfall," Royal Geographical Society, vol. 4, no. 3, pp. 329-352, 1978.

[35] L. Goddard and N. E. Graham, "Importance of the Indian Ocean for simulating rainfall anomalies over eastern and southern Africa," Journal of Geophysical Research, vol. 104, no. 16, pp. 19099-19116, 1999.

[36] P. J. Webster, "The large-scale structure of the tropical atmosphere," in General Circulation of the Atmosphere, Academic Press, London, UK, 1983.

[37] A. E. Okeyo, "Weather forecasting, in the influence of Lake Victoria on the convective systems over the Kenya highlands," in Proceedings of the International Conference on Short, Medium Range Weather Forecasting, WMO/IUGG NWP Symposium, Tokyo, August 1986.

[38] J. R. Mukabana and R. A. Pielke, "Investigating the influence of synoptic-scale monsoonal winds and mesoscale circulations on diurnal weather patterns over Kenya using a mesoscale numerical model," Monthly Weather Review, vol. 124, no. 2, pp. 224-243, 1996.

[39] E. K. A. M. Indeje, "Sensitivity of mesoscale systems over Kenya to changes in roughness length," Journal African Meteorological Society, vol. 3, pp. 19-33, 1998.

[40] M. J. McHugh, "Impact of South Pacific circulation variability on east African rainfall," International Journal of Climatology, vol. 26, no. 4, pp. 505-521, 2006.

[41] A. P. Williams and C. Funk, "A westward extension of the warm pool leads to a westward extension of the Walker circulation, drying eastern Africa," Climate Dynamics, vol. 37, no. 11-12, pp. 2417-2435, 2011.

[42] B. Lyon and D. G. Dewitt, "A recent and abrupt decline in the East African long rains," Geophysical Research Letters, vol. 39, no. 2, 2012.

[43] B. Lyon, "Seasonal drought in the Greater Horn of Africa and its recent increase during the March-May long rains," Journal of Climate, vol. 27, no. 21, pp. 7953-7975, 2014.

[44] L. J. Ogallo, "The spatial and temporal patterns of the East African seasonal rainfall derived from principal component analysis," International Journal of Climatology, vol. 9, no. 2, pp. 145-167, 1989.

[45] V. Ongoma, H. Chen, and G. W. Omony, "Variability of extreme weather events over the equatorial East Africa, a case 
study of rainfall in Kenya and Uganda," Theoretical and Applied Climatology, vol. 131, no. 1-2, pp. 295-308, 2016.

[46] E. Kalnay, M. Kanamitsu, R. Kistler et al., "The NCEP/NCAR 40-year reanalysis project," Bulletin of the American Meteorological Society, vol. 77, no. 3, pp. 437-471, 1996.

[47] H. B. Mann, "Nonparametric tests against trend," Econometrica, vol. 13, no. 3, pp. 245-259, 1945.

[48] M. G. Kendall, Rank Correlation Methods, Griffin, London, UK, 1975.

[49] V. Mosmann, A. Castro, R. Fraile, J. Dessens, and J. L. Sánchez, "Detection of statistically significant trends in the summer precipitation of mainland Spain," Atmospheric Research, vol. 70, no. 1, pp. 43-53, 2004.

[50] J. M. Moraes, H. Q. Pellegrino, M. V. Ballester et al., “Trends in hydrological parameters of southern Brazilian water shed and its relation to human induced changes," Water Resources Management, vol. 12, no. 4, pp. 295-311, 1998.

[51] W. Sun, R. Yu, J. Li, and W. Yuan, "Three-dimensional circulation structure of summer heavy rainfall in central North China," Weather Forecast, vol. 30, no. 1, pp. 238-250, 2015.

[52] J. R. Holton and G. J. Hakim, An Introduction to Dynamic Meteorology, Vol. 9780123848, Elsevier, New York, NY, USA, 5th edition, 2012. 

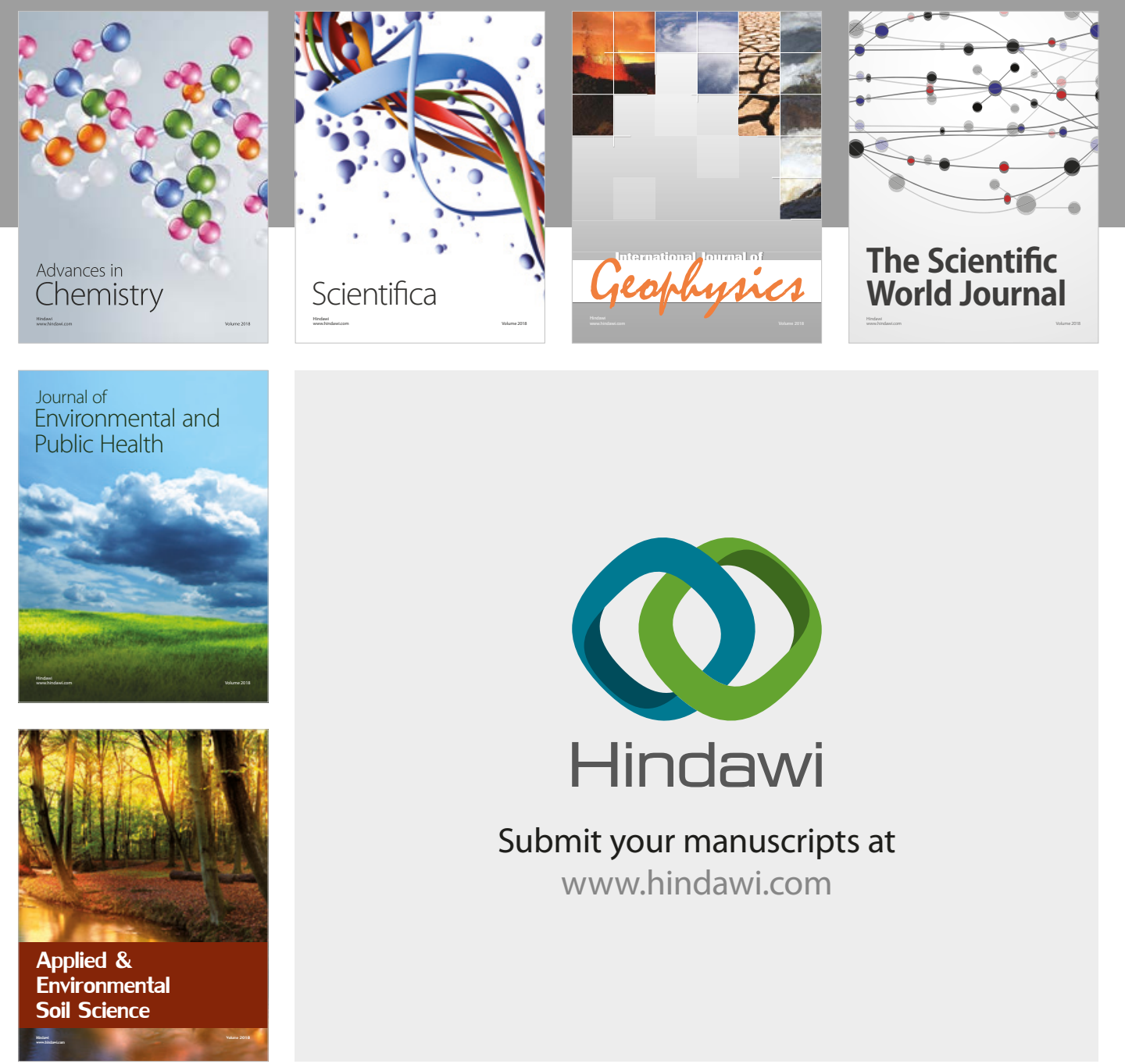

The Scientific

\section{World Journal}
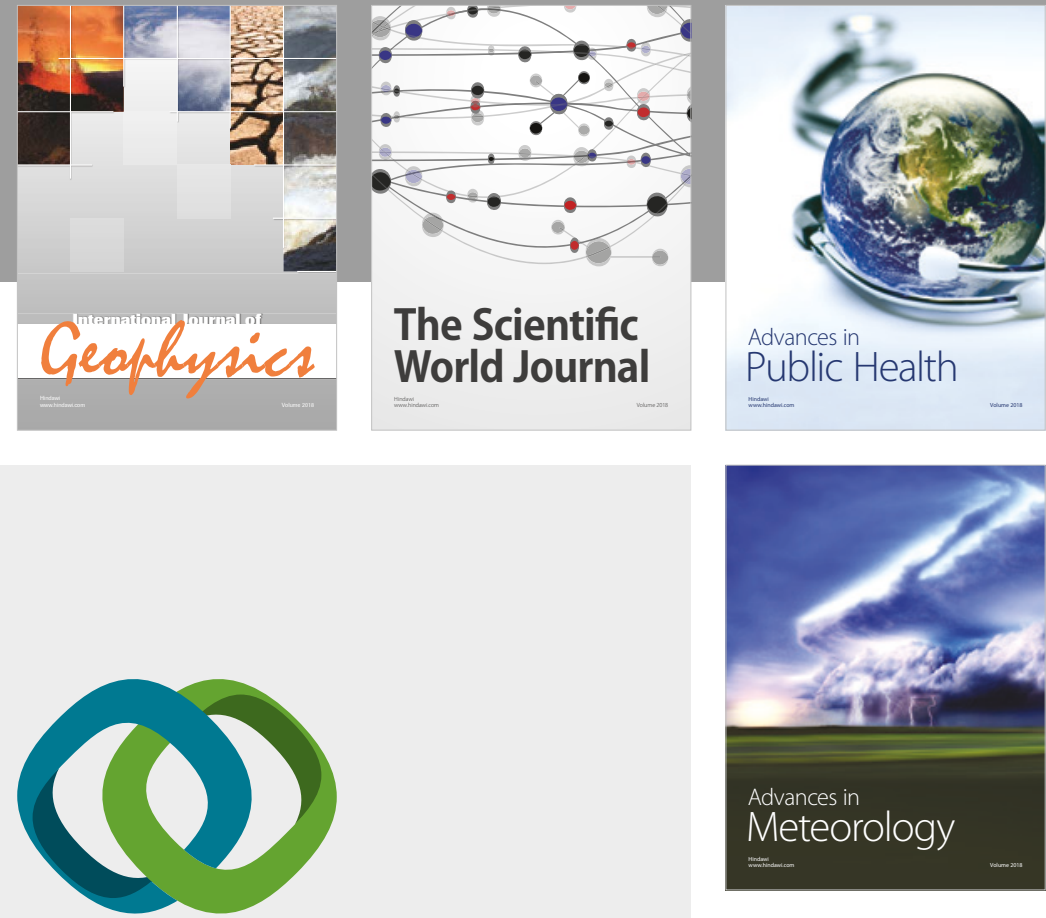

Advan

Public Health

\section{Hindawi}

Submit your manuscripts at

www.hindawi.com
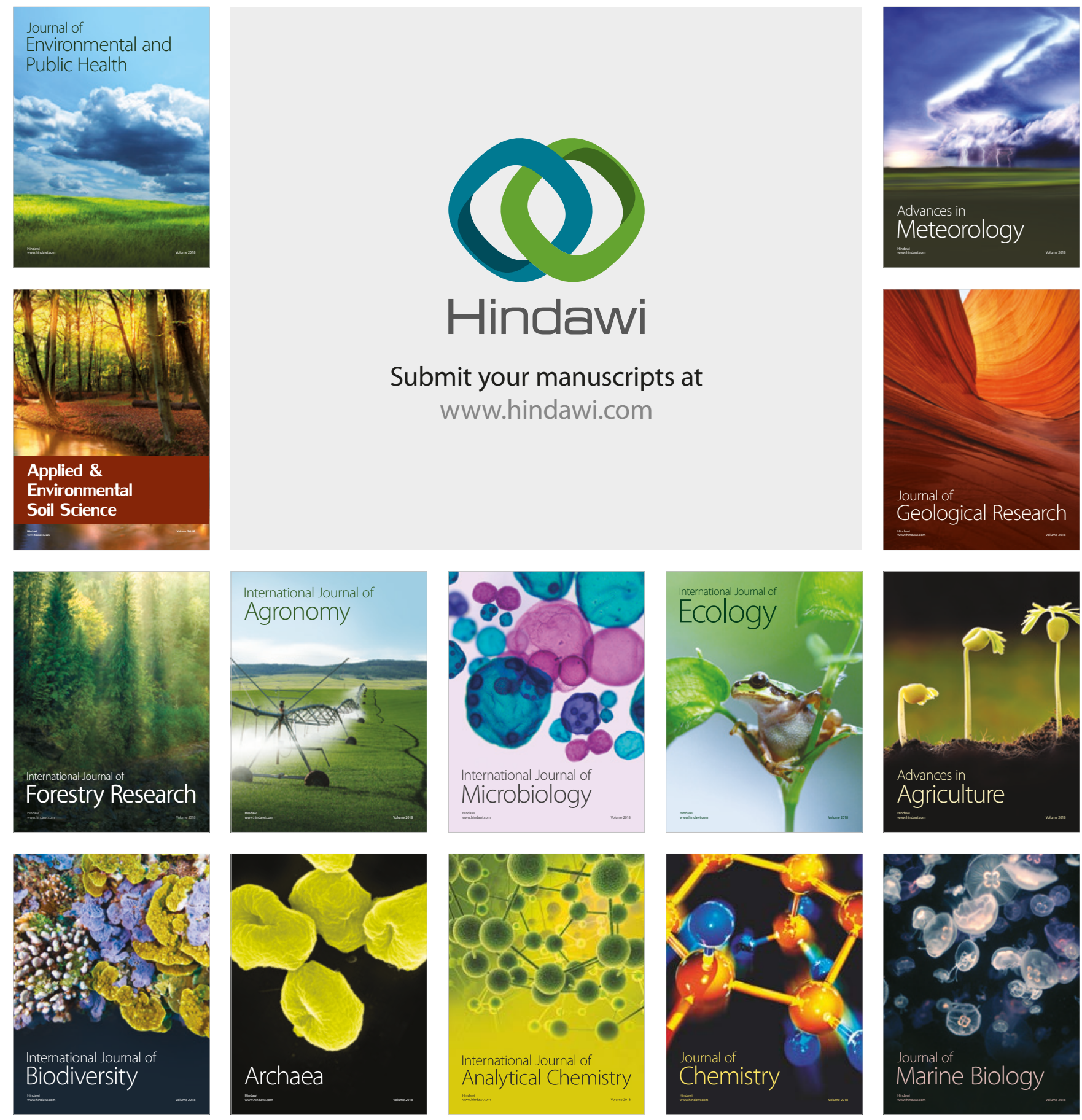